\title{
Adapting to the Weather: Lessons from U.S. History
}

\author{
Hoyt Bleakley and Sok Chul Hong
}

\begin{abstract}
An important unknown in understanding the impact of climate change is the scope of adaptation, which requires observations on historical time scales. We consider how weather across U.S. history (1860-2000) has affected various measures of productivity. Using cross-sectional and panel methods, we document significant responses of agricultural and individual productivity to weather. We find strong effects of hotter and wetter weather early in U.S. history, but these effects have generally been attenuated in recent decades. The results suggest that estimates from a given period may be of limited use in forecasting the longer-term impacts of climate change.
\end{abstract}

\begin{abstract}
major issue in forecasting the economic effects of climate change $\mathbf{X}_{\text {is the extent to which people can adapt to different weather patterns }}$ in the long term. If weather affects production or investment, adaptation can take several forms: adjusting the mix of inputs, choosing alternative technologies, or even developing a new technology that is more suited to the new climate. In addition, long-term changes in weather may lead to ecological changes, which might be amplified by human action, especially if property rights are not well-established (Diamond 1997; Libecap 2007). In any case, understanding the scope of long-term adjustment is key for measuring the impact of climate change.

While early approaches to this question relied on simulations of agronomic models, recent econometric work has used hedonic/cross-sectional or fixed-effect/panel methods. Hedonic models account for the price of land across areas with various factors, including climate variables. The estimated coefficients are interpreted as the discounted marginal value of
\end{abstract}

The Journal of Economic History, Vol. 77, No. 3 (September 2017). (C) The Economic History Association. All rights reserved. doi: 10.1017/S0022050717000675

Hoyt Bleakley is Associate Professor, Department of Economics, University of Michigan, 611 Tappan Avenue, Ann Arbor, MI 48109-1220. E-mail: hoytb@umich.edu. Sok Chul Hong is Associate Professor, Department of Economics, Seoul National University, 1 Gwanak-ro, Gwanak-gu, Seoul, 08826, South Korea. E-mail: sokchul.hong@snu.ac.kr (corresponding author).

We have benefited from comments and suggestions from Michael Greenstone, Paul Rhode, Wolfram Schlenker, Richard Steckel, Gary Libecap, Daniel Hamermesh, William Collins, and two anonymous referees, and from the participants in the workshops at the University of Chicago, UIUC, and Queen's University, Sogang University, Korea University, and Seoul National University, and in the seminars at NBER Universities' Research Conference, the American Economic Association Annual Meetings, and World Economic History Congress. Research reported in this article was supported by NIH grant number P01 AG10120 and the National Research Foundation of Korea Grant funded by the Korean Government (NRF-2011-327-B00079). 
these factors to land productivity. Important studies were conducted by Robert Mendelsohn, William Nordhaus, and Daigee Shaw (1994) and Wolfram Schlenker, Michael Hanemann, and Anthony Fisher (2005, 2006). If areas have had enough time to adapt to permanent features of their climate, then hedonic estimates can measure the long-term effects of climate. One limitation of such cross-sectional comparisons, however, is that they measure the effect of climate on land value plus the value of any omitted variables that happen to be correlated with the measures of climate employed. Moreover, the hedonic approach cannot provide direct evidence of adaptation: hedonic methods do not actually observe adaptation, but rather assume it. A complementary approach to this question uses panel and fixed-effect models that consider the impact of crossyear weather variations within an area (for example, Deschênes and Greenstone 2007; Schlenker and Roberts 2009; Deschênes, Greenstone, and Guryan 2009; Guitieras 2009; Dell, Jones, and Olken 2012; Burke, Hsiang, and Miguel 2015). Both methods have advantages but are limited by the range of technology during their sample window and, especially for panel methods, by the scope for adjustment over the time range implicit in their research design. Meaningful adaptation occurs over long periods of time; thus, direct evidence of adaptation requires observation over longer periods.

This study adopts aspects of both methodologies but from a longer-term perspective; we examine U.S. historical data spanning about 140 years. We investigate geospatial data on average weather conditions as well as historical weather information from measurement stations on temperature and rainfall. These data are matched to economic variables at the county and state levels. The United States is well-suited for this analysis for two reasons: first, the country has sufficient weather variability across areas to estimate these models; second, conformable data are available on both weather and economic variables over a long stretch of time.

We first consider the effect of weather on farm productivity. In the late 1800 s, the cross-section of farm value per acre by average temperature had an inverse U-shape. Below the median temperature, higher average temperature indicated more valuable farmland. Above the median, however, a warmer climate indicated lower farmland values. On the other hand, this negative effect for heat has attenuated, if not reversed, in recent decades. Specifically, in the second half of the twentieth century, farm value per acre increased monotonically with average temperature. A similar pattern is seen for rainfall: above the median, more average rain predicted lower farm values in the nineteenth century but higher values by the middle of the twentieth century. 
Next, we use panel/fixed-effect methods to estimate the response of farm productivity to variations in temperature and rainfall. We match a long-term weather variable (measured at the decade level) with farm value, and short-term weather variables (measured by annual averages in each census year) with farm output value. The response of both farmproductivity measures to high temperature or rainfall is estimated to be more negative in the early parts of the sample than in recent years. These results suggest a substantial economic effect of weather at various horizons but also point to a change in both the short- and long-term relationships between weather and farm productivity, particularly in warm and wet areas.

In the next section, we demonstrate instability over time in the relationship between weather in early life and later-life human capital, measured by occupation-based adult income, using a census sample of cohorts born from 1860 to 1960 . For those born prior to c.1920, being born in warmer or wetter areas was associated with substantially lower occupational income score in adulthood, but this correlation disappears among those born more recently. Similarly, using a fixed-effect estimator, we find effects on adult occupational income of interannual weather fluctuations in early childhood. However, this effect was strongest among those born earlier in the sample and is sharply attenuated among those born in the past 75 years. Once again, we find relationships between weather and occupational income that were strong in the past but are now considerably weaker.

The purpose of this study is to assess instability in the weather-productivity relationship over time, which measures adaptation to climate. We therefore do not characterize specific determinants of productivity change such as government policies and investments, market access, local infrastructure, and so on. Such analyses are quite limited due to a lack of historical variables and endogeneity problems. More importantly, those determinants could be part of adaptation to climate, and controlling for them would obscure the measurement of historical adaptation.

What is the relevance of these results to more contemporary issues? The timescale of anthropogenic climate change is best measured in centuries, with the greatest impacts occurring in the far future. This study suggests a simple thought experiment. Suppose we were in 1910 but were nevertheless charged with forecasting the impacts of climate change. We show that estimating standard models with circa 1900 data yields results quite different from those obtained from estimating such models with circa 2000 data. Therefore, estimates from the turn of one century would 
be poor guides to forecasting climate-change impacts in the century that follows. However, the recent literature is doing something similar by using estimates from the late twentieth century to forecast the systematic response of economic variables to weather or climate over the course of the twenty-first and twenty-second centuries. The results that follow suggest that greater caution is called for when conducting such exercises.

\section{BACKGROUND AND RELATED LITERATURE}

The effect of climate change on agriculture was extensively studied in the 1980s amid the increasing worldwide concern about global warming (Houghton, Jenkins, and Ephraums 1990). The early approach was based on agronomic models of production functions (Adams 1989; Adams et al. 1990; inter alia). This traditional approach models a function of crop production from empirical or experimental results. Climatic components such as temperature and precipitation are used as key input variables. Researchers simulate the change in crop yield by varying the input variables. Using this production-function approach, various studies have predicted that U.S. agriculture would experience significant hardship because of global warming. This method is useful and accurate if the response of crop yield to weather is constant across space and time. However, it can be misleading if the response changes over time. For example, new technologies (including plant varieties) and economic conditions might reduce the negative effects of drought and extreme temperature on crop production-that is, adaptation.

Mendelsohn, Nordhaus, and Shaw (1994) emphasized the scope of adaptations and adjustments farmers ordinarily make in response to different economic and environmental conditions. For example, adaptive and profit-maximizing farmers will switch their main crop from wheat to corn as local temperature increases. Alan Olmstead and Paul Rhode $(2008,2011)$ observed the converse in U.S. economic history, where farmers have adopted innovative varieties that dramatically increased the range over which certain crops can be grown. Thus, without considering adaptation or substitution, the production-function approach can overestimate the agricultural damage from climate change.

As an alternative approach, Mendelsohn, Nordhaus, and Shaw (1994) developed a hedonic price model. Based on David Ricardo's value theory, the hedonic approach assumes that the economic value of adaptive activities for climate change is reflected in land rent. In other words, if farms had enough time to adapt to climate change, the land rent will be equal to 
the net yield of the highest and best use of the land. ${ }^{1}$ They measured land rent with farm value, which should be the present value of future rent. By running a regression of farm value on climatic, environmental, economic, and agronomic variables, they estimated the discounted marginal value or price sensitivity of these factors to land productivity. They found a significantly lower impact of global warming on U.S. agriculture than did the traditional production-function approach. Although the newly developed method and findings have influenced subsequent studies on climate change, the study does not actually observe the adaptation to climate or dynamic adjustment because it conducted cross-sectional comparisons in c.1980. Instead, it assumes adaptation.

Other limitations of the hedonic approach have been reported by several studies. William Cline (1996) questioned the validity of applying cross-sectional analyses of current land values to predict future globalwarming impacts because the relative price of grain will change due to the global reduction in grain yield. Roy Darwin (1999) argued that the model produced estimates that violate basic agricultural principles, as it insufficiently captured the effect of irrigation on farmland value. Similarly, Schlenker, Hanemann, and Fisher (2005) showed that the economic effects of climate change on agriculture must be assessed differently in dry land and irrigated areas, emphasizing the role of irrigation and water supply in the hedonic approach.

The validity of the hedonic regression was carefully examined by Olivier Deschênes and Michael Greenstone (2007), who recognized that unobserved characteristics are spatially correlated, such that the standard ordinary least squares (OLS) formulas used in the hedonic regression can be incorrect. In this case, the hedonic approach can confound climate with other regional factors that happen to be correlated with the measures of climate employed. As a possible solution to the omitted variable bias issue, Deschênes and Greenstone (2007) proposed a fixed-effects model that uses the across-year variation in temperature and precipitation within counties to estimate the effect of climate change on agricultural profits and yields. More recently, Schlenker and Michael Roberts (2009) employed a large panel of crop yields and daily weather variables spanning most U.S.

\footnotetext{
${ }^{1}$ Land rent reflects not only the economic value of one country's adaptive activities for climate change but can also be affected by the relative difference in adaptation across countries. For example, if the adaptation in non-U.S. countries was even less successful than that in the United States, U.S. land rent and relative productivity could increase. Furthermore, climate change could affect the global supply of substitutes or complements for U.S.-produced goods, altering the terms of trade for the United States (and for its regions).
} 
counties from 1950 to 2005 . Using a fixed-effects model, they estimated the temperature thresholds above which crop yields sharply decline. The findings suggest that global warming might severely damage U.S. crop yields within the century, contrary to the prediction of Deschênes and Greenstone (2007).

Each of those previous studies has an advantage for understanding the effect of climate change on agriculture. One advantage of the hedonic approach is that it can account for adaptive behavior (for example, crop choice and developing new agricultural technologies), whereas the fixedeffects model can resolve the omitted variable bias problem. Nevertheless, the significant unknown in existing studies is the scope of adaptation. As noted earlier, this is not actually observed but is assumed in the hedonic approach. The studies based on the fixed-effects model are limited by the time window employed in their research design.

Meaningful adaptation takes place over a long time span; therefore, direct evidence of adaptation requires observation over longer periods of time. One strength of this study is that it harnesses the advantages of hedonic and fixed-effects methods. However, its greatest strength is that it extends the time window to span 140 years, throughout which humans have created various technological adaptations to the weather.

Relatedly, Olmstead and Rhode (2011) provided evidence of specific adaptations by examining how North American wheat farmers overcame significant climatic challenges over the past two centuries. Richard Hornbeck (2012) examined how agricultural adjustment occurred in the counties severely eroded by the 1930s American Dust Bowl throughout the Depression to the 1950s. This study investigates general patterns of adaptation to climate instead; therefore, their work is complementary to ours.

Finally, a few studies have examined the effect of weather in terms of non-agricultural outcomes. Most have focused on identifying the causal effect of climatic variables on outcomes such as mortality, health, educational attainment, and income (Deschênes, Greenstone, and Guryan 2009; Maccini and Yang 2009), which we will discuss at greater length in a later section. Recently, Alan Barreca et al. (2015) estimated that the negative impact of extreme heat on mortality significantly attenuated from 1900 to 2004 by employing cross-sectional and panel methods. They argued that existing studies have ignored long-term adaptation to changes in climatic variables that evolve over decades or more and emphasize that more adaptation becomes available in the future. 


\section{DATA}

This study merges historical weather variables with measures of farm productivity at the county level and of income (proxied by occupational scores) at the individual level. This section briefly explains how each variable is constructed or obtained. Detailed information on data sources and related issues is provided in Appendix 1.

First, the construction of historical county weather variables is based on the Nineteenth-Century U.S. Climate Data Set Project developed by the National Climate Data Center and the Long-Term Daily and Monthly Climate Records from the Stations across the Contiguous United States provided by the U.S. Historical Climatology Network. Both datasets report monthly mean temperature and monthly accumulated precipitation according to thousands of weather stations that have existed over the past two centuries. However, weather information is not available for all counties. Weather variables for counties without historical weather stations in certain periods need to be estimated. We use a geostatistical technique called "Kriging," an algorithm that imputes the climatic value at a given (target) location as a weighted sum of the data values at surrounding locations. Kriging assigns weights with inverse distance squared among locations; it assigns a lower weight to surrounding weather stations located at a greater distance from the target location (Stein 1999). Using this method, we estimate monthly mean temperatures and monthly accumulated precipitation by county and for every month from 1860 to $2000 .^{2}$ Then, we utilize the monthly estimation results to calculate annual, decadal, and centurial mean temperature and precipitation at the countyor state-level according to the research designs in later sections.

Second, this study uses two measures of county farm productivity found in Historical, Demographic, Economic, and Social Data: The United States, 1790-2002 (Haines and ICPSR 2010): farm value per farmland acre and farm output value per farmland acre. Farm value is defined as the value of all farmland, housing, and outbuildings at the time of census enumeration. Although it is available from the 1850 agricultural census, we use the variable only from 1870 to 2000, considering the periods when the quality of estimated weather variables was acceptable. Farm output value is the total value of all farm products within the year prior to the enumeration day. ${ }^{3}$ However, the variable is not found in the earlier source for the census years of 1910, 1920, and 1930.

\footnotetext{
${ }^{2}$ We test the validity of the Kriging estimation in Appendix 1.

${ }^{3}$ There is a double counting issue in calculating farm output value because some crops, particularly corn and hay, are used for feeding livestock. We discuss the issue in more detail later and statistically test whether measurement error due to double counting can affect our main estimation.
} 
Third, the changes of county boundaries matter when county fixed effects are considered. To partially fix the problem, we adjust these county variables from 1880 to 2000 on the 1870 county boundary, using the area-weighted average method. ${ }^{4}$ We use every 10 years from 1870 on, for convenience, to refer to each census year. For some years, the actual year when each census was conducted is different from the referred year in this article. For example, the 2000 agricultural census was surveyed in 1997.

Fourth, as a measure of individual income, we use the occupational income score, which is available for a large number of censuses. The variable represents the median total income by disaggregated occupational categories that were calibrated using data from the 1950 census. Occupation has been recorded by the census for more than a century; thus, the income proxy is available for a substantial stretch of cohorts. We use micro samples from the 1880 and 1900-1990 IPUMS-Integrated Public Use Microdata Series (Ruggles et al. 2015) and then select adult white males aged 20 to 65 who were born between 1860 and 1960. We choose 1860 as the earliest year of birth in view of the low quality of the weather data in earlier years. The units of observation of the unbalanced panel are cohorts, defined by year of birth and state of birth.

\section{WEATHER AND FARM PRODUCTIVITY}

\section{Long-Term Weather Conditions and County Farm Value}

We first investigate the historical pattern of the relationships between the county average of farm value and its weather conditions using scatter plots. This cross-sectional analysis is intended to show that county farm value has adapted to the permanent features of local weather over time in the United States. Although the range of temperature and precipitation is substantial in the United States, the results that follow do not specifically address the over-time instability of such relationships outside the United States.

For the six selected decades, the upper panel of Figure 1 plots the logarithm of each county's average farm value per acre against its decadal average of annual mean temperature (Fahrenheit), which is calculated

\footnotetext{
${ }^{4}$ This adjustment of county boundary change can cause biases if new county areas had quite different climate over time. We test this possibility by analyzing (1) unbalanced panel data without adjustment in Appendix 3 and (2) only counties whose boundaries have not changed from 1870 to 2000 in Appendix 3. The results suggest that the adjustment does not undermine the key findings or implications of this study.
} 
Decadal Average of County Annual Mean Temperature
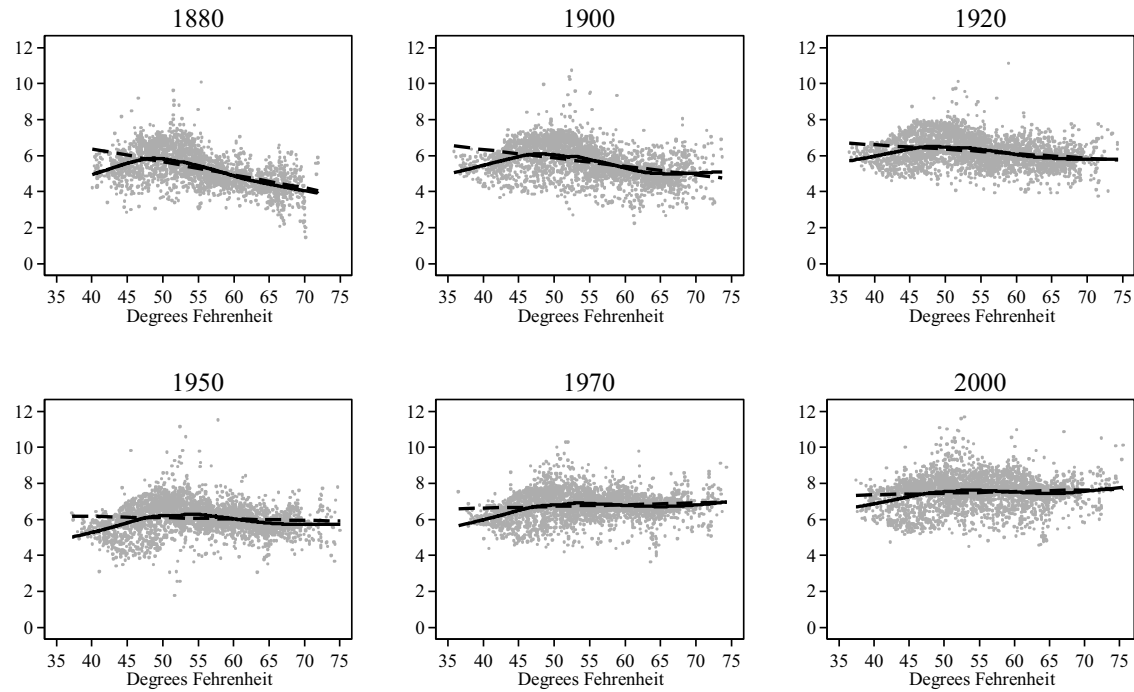

Decadal Average of County Annual Accumulated Precipitation
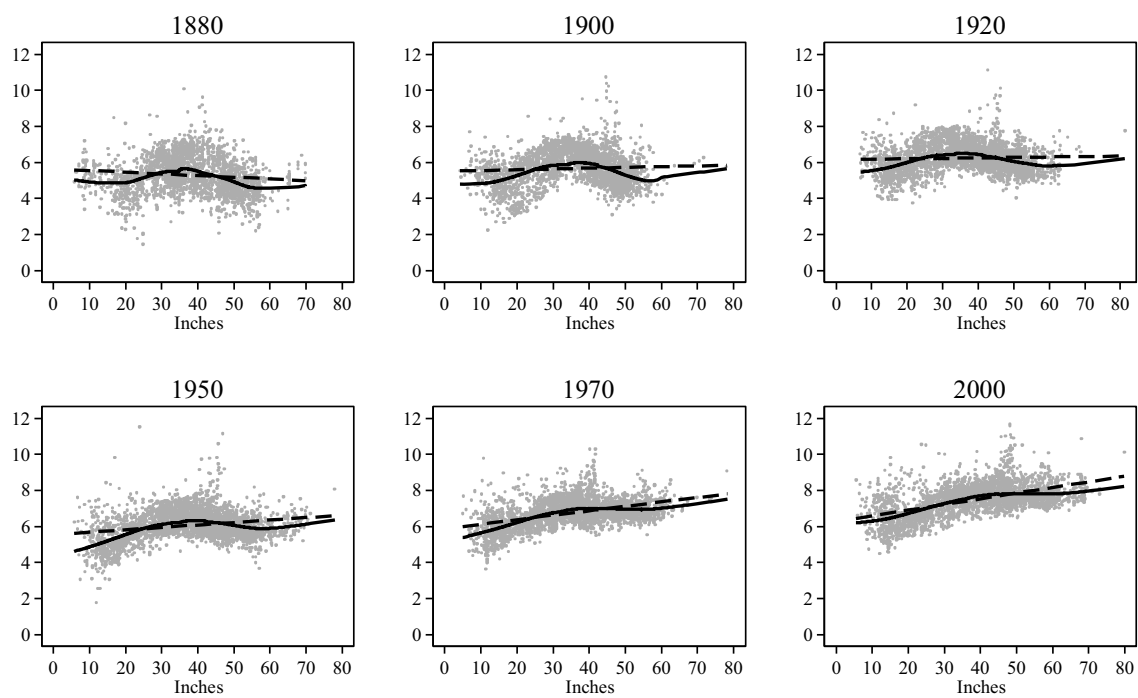

FIGURE 1

\section{LOG COUNTY AVERAGE FARM VALUE PER ACRE BY 10-YEAR AVERAGE TEMPERATURE AND PRECIPITATION}

Notes: Each weather variable on the $x$-axis denotes the 10-year average of annual weather values prior to each census year. The $y$-axis denotes the logarithm of the county average farm value per farmland acre. Solid curves are lowess fit curves, and dotted lines are linear fit lines.

Sources: Authors' calculations based on farm statistics found in the historical census records (Haines and ICPSR 2010) and Kriging-interpolated weather variables. Details are provided in Appendices 1 and 2. 
for the 10 years prior to the year of census. ${ }^{5} \mathrm{We}$ also put a linear trend line and a lowess fit curve on each decade's scatter plot. The bivariate diagrams suggest that the relevance of temperature to farm value gradually changed across decades. High temperatures depressed farm value in the second half of the nineteenth century, but this negative association weakened throughout the early twentieth century. In recent decades, farm value has been (marginally) increasing with temperature. In addition, a quadratic relationship is evident in the late nineteenth century, with a peak of around $50^{\circ} \mathrm{F}$. However, this inverse U-shape relationship has attenuated over time and appears non-significant in recent decades.

A similar historical pattern is observed between county farm value and decadal averages of annual accumulated precipitation, which is presented in the lower panel of Figure 1. An inverse U-shape relationship is observed until the early twentieth century. For the counties whose decadal average of annual accumulated precipitation was below about 35 inches, farm value increased with precipitation. However, a high level of precipitation above this threshold depressed farm value. The nonlinear pattern indicates a negative correlation between county farm value and precipitation in the late nineteenth century, and the negative slope became flat and non-significant throughout the early twentieth century. The attenuation of the negative relationship and inverse U-shape relationship accelerated toward the late twentieth century; county farm value has been rapidly increasing with precipitation levels in recent decades.

This bivariate cross-sectional analysis shows that (a) adaptation to hot and wet weather can be clearly observed if we look at adaptation across longer time periods and that (b) the pattern of adaptation has occurred very gradually. However, this hedonic approach does not determine whether this adaptation to permanent weather conditions resulted from a change in the climate effect or a change in the effect of other local agricultural, socioeconomic, or demographic characteristics that happen to be correlated with weather variables.

\section{Fixed-Effects Model}

As a complementary approach, we use a fixed-effects model and compare it with the cross-sectional results described earlier. Equation (1) estimates the historical pattern of the effect of long-term weather on farm

\footnotetext{
${ }^{5}$ For example, the decadal weather variable for 1880 in Figure 1 is estimated as the average for 1870 to 1879 . Thus, we assume that farm value depended on farm productivity affected by weather condition in the 1870 s.
} 
value, controlling for state- and year-specific improvements in agricultural technologies and time-invariant county factors: ${ }^{6}$

$$
Y_{i j t}=\alpha W_{i j t}+X_{i j t} \Gamma+\sum_{t=1880}^{2000}\left(\beta_{t} D_{t}^{\prime} W_{i j t}+D_{t}^{\prime} X_{i j t} \Pi_{t}\right)+\delta_{t}+\delta_{j t}+\delta_{i}+\varepsilon_{i j t},
$$

where $Y_{i j t}$ is the logarithm of county $i$ (in state $j$ )'s average farm value per acre measured at census year $t, W_{i j t}$ is the decadal average of each weather variable (temperature or precipitation) in county $i, X_{i j t}$ are vectors of county-level agricultural controls and constant terms, $D_{t}$ are dummies indicating year $t, \delta_{t}$ are year fixed effects, $\delta_{j t}$ are state-by-year fixed effects, and $\delta_{i}$ are county fixed effects. The latter two sets of fixed effects appear only in some specifications, as noted later. As county-level controls, we use county population density, the ratio of white population to county population, the ratio of farmland to total available county area, and the estimated number of farmers per farmland acre. Sources and the construction of each control variable are discussed in Appendix 2. Equation (1) considers the impact of cross-decade variation in weather within a county and focuses only on the linear relationship between county farm value and weather variables. In the estimation model, the reference year is 1870. The coefficients $\beta_{t}$ estimate the extent to which the response of farm value at census year $t$ to local temperature or precipitation differed from its level in 1870. Finally, the equation is estimated using weighted ordinary least squares regressions. We calculated standard errors of estimated weather values using the Kriging process and used the inverse of the standard errors as regression weights.

Each panel in Figure 2 graphically presents the coefficient $\beta_{t}$ for temperature and precipitation. Dotted lines represent the results of estimating equation (1) including only year fixed effects from three types of fixed effects; dashed lines represent the results with additional control for state-by-year fixed effects; solid lines represent the estimation results with county fixed effects. ${ }^{7}$

Figure 2 shows that the effect of variation in long-term temperature and rainfall on farm value rapidly changed until the mid-twentieth century. The increasing trend of $\beta_{t}$ over the years implies that high temperatures and rainfall became more beneficial to farm value as time passed. Then, $\beta_{t}$ remains stable after the period between 1960 and 1970, suggesting that

\footnotetext{
${ }^{6}$ Agricultural control variables are limited because those that appear in some census years are frequently unavailable in others. The use of fixed effects models partially alleviates this limitation.

${ }^{7}$ In the regressions for Figure 2, we control for county-level agricultural variables and constant terms denoted by variable $X$ noted earlier. All coefficients shown in Figure 2 are statistically significant at the 99 percent confidence level. See Appendix Table 3 for detailed estimation results.
} 

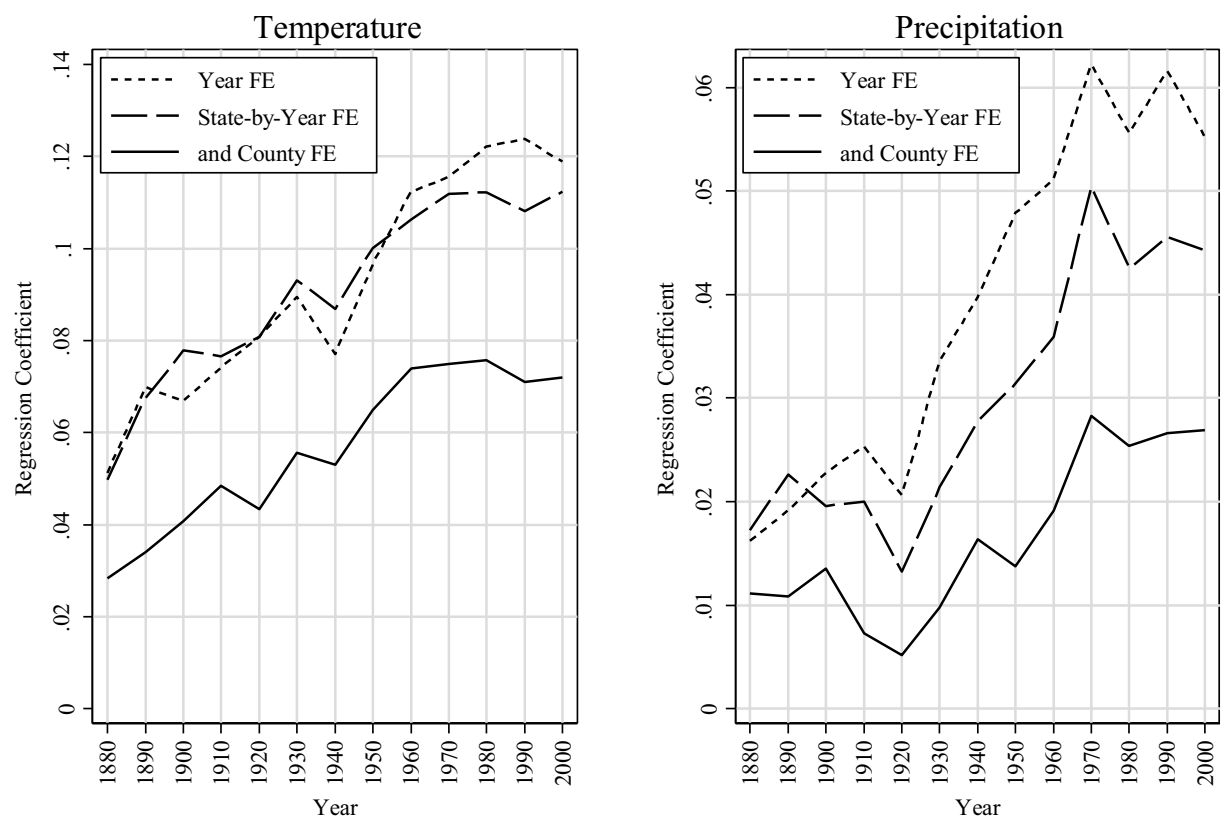

FIGURE 2

TREND OF THE ESTIMATED EFFECT OF LONG-TERM TEMPERATURE AND PRECIPITATION ON COUNTY FARM VALUE PER ACRE

Notes: We ran the weighted regressions of the logarithm of county average farm value on the 10-year average of annual mean temperature or annual accumulated precipitation prior to each census year, standard controls, and their interactions with the dummies that indicate the 1880 2000 census years, per equation (1). Thus, the reference year is 1870. Each panel is the graphical presentation of regression coefficients of each weather variable. The dotted and dashed lines are the estimation results that employ year and state-by-year fixed effects, respectively; the solid lines additionally employ county fixed effects. The detailed regression results with county fixed effects are reported in Appendix Table 3 in Appendix 3.

Sources: Authors' calculations.

adaptation to hot and rainy weather slowed in recent decades. The estimated coefficients depend on the use of fixed effects. County fixed-effects models estimate smaller effects of cross-decade variation in weather on farm value relative to 1870 levels than do the year or state-by-year fixed-effects models. Accordingly, a slower adaption to hot and rainy weather is estimated when county fixed effects are used. This means that the historical pattern observed in Figure 1 can be explained largely by non-weather unobservable county characteristics that are correlated with county weather conditions. ${ }^{8}$

\footnotetext{
${ }^{8}$ In the panel/fixed-effects analysis, we use county boundary-adjusted data. In Appendix 3, we compare the result in this section with the estimation result based on data without the adjustment and find that the use of county boundary-adjusted data does not cause critical problems in estimating fixed-effect models.
} 


\section{Measuring Adaptation to the Weather across Centuries}

The key findings noted earlier are as follows: the effect of hot and rainy weather on farm value substantially changed over the past two centuries, and the turnover of the historical pattern occurred chiefly throughout the first half of the twentieth century. Thus, if we compare the effect between the beginning (late nineteenth century) and end (late twentieth century) periods of the sample time window, the magnitude of the adaptation can be estimated more accurately.

For the comparison, we select two periods: 1870 to 1900 and 1970 to 2000. In columns (1) and (2) of Table 1, we run weighted regressions of county farm value on decadal weather variables, the standard controls used earlier, and state dummies (in other words, state fixed effects) for each century. Column (3) estimates the significance of the difference in marginal effects between the two centuries by examining interactions between all control variables and a dummy that indicates the census year in the nineteenth century $\left(D_{19}\right)$. The estimation model also controls for century-by-state fixed effects. Panels A and B estimate the marginal effect of temperature (denoted by $T$ in Table 1 ) and precipitation $(P)$ on farm value, respectively. We report only the coefficients and standard errors for weather variables in Table 1. The results of columns (1) and (2) reflect the long-term relationship between decadal weather conditions and farm value shown in Figure 1. The coefficient of the weather variables interacted with $D_{19}$ in column (3) shows that the cross-century change in the effect is statistically significant.

Column (4) uses state-by-year fixed effects rather than state-by-century fixed effects and also controls for county fixed effects, as follows:

$$
Y_{i j t}=\alpha W_{i j t}+\beta W_{i j t} D_{19}+X_{i j t} \Gamma+X_{i j t} D_{19} \Pi+\delta_{t}+\delta_{j t}+\delta_{i}+\varepsilon_{i j t},
$$

where $i, j$, and $t$ denote county, state, and census year, respectively. This slightly changes the marginal effect of weather in each century and the magnitude of its difference across centuries ( $\beta$ in equation [2]). However, the difference remains significant and similar to that seen in Figure 2.

The purpose of the analysis throughout is not to characterize the agricultural and policy determinants of farm productivity but rather to assess instability in the weather-productivity relationship over time, which we argue measures adaptation (defined broadly) over the centuries. Many endogenous factors affect farm productivity, such as government policies 
TABLE 1

CENTURY DIFFERENCE IN THE RESPONSE OF COUNTY FARM VALUE TO LONG-TERM WEATHER CONDITIONS

Dependent Variable: $\ln$ (county average farm value per acre)

(1)

(2)

(3)

(4)

\begin{tabular}{|c|c|c|c|c|}
\hline Period of sample & Nineteenth Century & Twentieth Century & Both Centuries & Both Centuries \\
\hline State FE & $\mathrm{x}$ & $\mathrm{x}$ & & \\
\hline State $\times$ Century FE & & & $\mathrm{x}$ & \\
\hline State $\times$ Year FE & & & & $\mathrm{x}$ \\
\hline County FE & & & & $\mathrm{x}$ \\
\hline
\end{tabular}

Panel A: Only Temperature $(T)$

\begin{tabular}{|c|c|c|c|c|}
\hline \multirow[t]{2}{*}{$T$} & $-0.0219 * * *$ & 0.0063 & 0.0063 & $0.0231 * * *$ \\
\hline & $(0.0047)$ & $(0.0047)$ & $(0.0047)$ & $(0.0088)$ \\
\hline \multirow[t]{2}{*}{$T \times D_{19}$} & & & $-0.0282 * * *$ & $-0.0470 * * *$ \\
\hline & & & $(0.0055)$ & $(0.0056)$ \\
\hline Adj. $R^{2}$ & 0.690 & 0.430 & 0.823 & 0.949 \\
\hline
\end{tabular}

Panel B: Only Precipitation $(P)$

\begin{tabular}{lcccc}
\hline$P$ & $-0.0100 * * *$ & $0.0297 * * *$ & $0.0297 * * *$ & $0.0114 * * *$ \\
& $(0.0021)$ & $(0.0019)$ & $(0.0019)$ & $(0.0025)$ \\
$P \times D_{19}$ & & $-0.0396 * * *$ & $-0.0162 * * *$ \\
& & $(0.0026)$ & $(0.0030)$ \\
Adj. $\mathrm{R}^{2}$ & 0.690 & 0.474 & 0.830 & 0.948
\end{tabular}

Panel C: Temperature $(T)$ and Precipitation $(P)$

\begin{tabular}{lcccc}
\hline$T$ & $-0.0164 * * *$ & -0.0031 & -0.0031 & $0.0246^{* * *}$ \\
& $(0.0051)$ & $(0.0043)$ & $(0.0043)$ & $(0.0080)$ \\
$T \times D_{19}$ & & $-0.0133^{* *}$ & $-0.0472^{* * *}$ \\
& & $(0.0056)$ & $(0.0057)$ \\
$P$ & & & \\
& & & $0.0305^{* * *}$ & $0.0098^{* * *}$ \\
$P \times D_{19}$ & $(0.0020)$ & $(0.0019)$ & $(0.0019)$ & $(0.0024)$ \\
& & & $-0.0403 * * *$ & $-0.0119 * * *$ \\
$\left(T-T_{m}\right) \times\left(P-P_{m}\right)$ & & $(0.0026)$ & $(0.0028)$ \\
& & & $-0.0005^{* *}$ & 0.0001 \\
& $(0.0003)$ & $(0.0002)$ & $(0.0002)$ & $(0.0004)$
\end{tabular}


TABLE 1 (CONTINUED)

CENTURY DIFFERENCE IN THE RESPONSE OF COUNTY FARM VALUE TO LONG-TERM WEATHER CONDITIONS

Dependent Variable: $\ln ($ county average farm value per acre)

(1)

(2)

(3)

(4)

Panel C: Temperature $(T)$ and Precipitation $(P)$

\begin{tabular}{|c|c|c|c|c|}
\hline \multicolumn{3}{|l|}{$\left(T-T_{m}\right) \times\left(P-P_{m}\right) \times D_{19}$} & & \\
\hline Adj. $R^{2}$ & 0.692 & 0.475 & 0.830 & 0.950 \\
\hline Observations & 8,432 & 8,432 & 16,864 & 16,864 \\
\hline
\end{tabular}

* = Significant at the 90 percent level.

** = Significant at the 95 percent level.

*** = Significant at the 99 percent level.

Notes: We estimate the century difference in the response of county farm value to long-term weather conditions. For the regressions, we select the representative periods of two centuries: the decades ending with $1870,1880,1890$, and 1900 for the nineteenth century, and the decades ending with 1970, 1980, 1990, and 2000 for the twentieth century. The long-term weather conditions are measured by the 10 -year average of annual mean temperature $(T)$ and annual accumulated precipitation $(P)$ from each census year, respectively. $T_{m}$ and $P_{m}$ denote the sample mean of temperature and precipitation variables, respectively. $D_{19}$ denotes the dummy variable that indicates the census years in the nineteenth century (in other words, 1870, 1880, 1890, or 1900). In all the regression models, we control for each county's population density, ratio of white populations, ratio of farmland to total county area, and number of farmers per farmland acre in each census year. Columns (1) and (2) estimate the marginal effect of weather on farm value in each century. Columns (3) and (4) estimate whether the marginal effect is significantly different across the centuries by pooling both centuries and adding the interaction terms between weather variables and $D_{19}$, per equation (2). However, we use different fixed-effect models in columns (3) and (4). Weighted regressions are used in all the estimations, where the regression weight is the inverse value of the weather estimates' standard errors. Panels A and $\mathrm{B}$ employ temperature and precipitation, respectively; Panel $\mathrm{C}$ employs both variables together. The table reports only the coefficients of key variables. The standard errors of regression coefficients, reported in parentheses, are clustered on county.

Sources: Authors' calculations.

and investments, local infrastructure like railroads, and so on. Of course, fixed-effects models absorb all the fixed county-level and state-by-year characteristics, be they endogenous or exogenous (Figure 2 and Table 2 show similar coefficients with or without such fixed effects). However, our use of additional controls is limited by several considerations. First, few potential control variables are consistently measured across the censuses. Second, because of a lack of plausible instruments, we would not be able to correct the endogeneity problems for the policy and infrastructure variables, which are likely biased by reverse causality and omitted variables. Third and most importantly, such factors are investments in adapting to circumstances, including the climate. We would not want to remove such adaptation from the estimates, because they are part of the story. ${ }^{9}$

\footnotetext{
${ }^{9}$ In the Online Appendix, we present a speculative analysis of mechanisms that might be at play in understanding the instability of the weather-productivity relationships over time.
} 
TABLE 2

CENTURY DIFFERENCES IN THE RESPONSE OF COUNTY FARM OUTPUT VALUE TO SHORT-TERM WEATHER CONDITIONS

Dependent Variable: $\ln ($ county average farm output value per acre)

(1)

(2)

(3)

(4)

\begin{tabular}{|c|c|c|c|c|}
\hline Period of sample & Nineteenth Century & Twentieth Century & Both Centuries & Both Centuries \\
\hline State FE & $\mathrm{x}$ & $\mathrm{x}$ & & \\
\hline State $\times$ Century FE & & & $\mathrm{x}$ & \\
\hline State $\times$ Year FE & & & & $\mathrm{x}$ \\
\hline County FE & & & & $\mathrm{x}$ \\
\hline \multicolumn{5}{|c|}{ Panel A: Only temperature $(T)$} \\
\hline $\bar{T}$ & $-0.0330 * * *$ & $0.0119^{*}$ & $0.0119^{*}$ & $0.0327 * * *$ \\
\hline & $(0.0038)$ & $(0.0064)$ & $(0.0064)$ & $(0.0101)$ \\
\hline$T \times D_{19}$ & & & $\begin{array}{c}-0.0449 * * * \\
(0.0067)\end{array}$ & $\begin{array}{c}-0.0416^{* * *} \\
(0.0086)\end{array}$ \\
\hline Adj. $\mathrm{R}^{2}$ & 0.520 & 0.476 & 0.684 & 0.841 \\
\hline \multicolumn{5}{|c|}{ Panel B: Only precipitation $(P)$} \\
\hline$P$ & $\begin{array}{l}0.0014 * \\
(0.0008)\end{array}$ & $\begin{array}{c}0.0152 * * * \\
(0.0018)\end{array}$ & $\begin{array}{c}0.0152 * * * \\
(0.0018)\end{array}$ & $\begin{array}{c}0.0074 * * * \\
(0.0023)\end{array}$ \\
\hline$P \times D_{19}$ & & & $\begin{array}{c}-0.0138 * * * \\
(0.0020)\end{array}$ & $\begin{array}{c}-0.0114 * * * \\
(0.0031)\end{array}$ \\
\hline Adj. $R^{2}$ & 0.508 & 0.489 & 0.686 & 0.840 \\
\hline \multicolumn{5}{|c|}{ Panel C: Temperature $(T)$ and precipitation $(P)$} \\
\hline$T$ & $\begin{array}{c}-0.0315 * * * \\
(0.0036)\end{array}$ & $\begin{array}{l}0.0111^{*} \\
(0.0062)\end{array}$ & $\begin{array}{l}0.0111^{*} \\
(0.0062)\end{array}$ & $\begin{array}{c}0.0298 * * * \\
(0.0096)\end{array}$ \\
\hline$T \times D_{19}$ & & & $\begin{array}{c}-0.0426^{* * *} \\
(0.0067)\end{array}$ & $\begin{array}{c}-0.0378 * * * \\
(0.0086)\end{array}$ \\
\hline$P$ & $\begin{array}{c}0.0008 \\
(0.0008)\end{array}$ & $\begin{array}{c}0.0156^{* * *} \\
(0.0019)\end{array}$ & $\begin{array}{c}0.0156^{* * *} \\
(0.0019)\end{array}$ & $\begin{array}{c}0.0082 * * * \\
(0.0021)\end{array}$ \\
\hline$P \times D_{19}$ & & & $\begin{array}{c}-0.0148 * * * \\
(0.0020)\end{array}$ & $\begin{array}{c}-0.0110^{* * *} \\
(0.0030)\end{array}$ \\
\hline$\left(T-T_{m}\right) \times\left(P-P_{m}\right)$ & $\begin{array}{c}0.0003 * * * \\
(0.0001)\end{array}$ & $\begin{array}{l}-0.0003 \\
(0.0003)\end{array}$ & $\begin{array}{l}-0.0003 \\
(0.0003)\end{array}$ & $\begin{array}{c}-0.0008^{* *} \\
(0.0003)\end{array}$ \\
\hline$\left(T-T_{m}\right) \times\left(P-P_{m}\right) \times D_{19}$ & & & $\begin{array}{c}0.0006^{* *} \\
(0.0003)\end{array}$ & $\begin{array}{c}0.0004 \\
(0.0004)\end{array}$ \\
\hline Adj. $R^{2}$ & 0.520 & 0.490 & 0.690 & 0.842 \\
\hline Observations & 8,432 & 8,432 & 16,864 & 16,864 \\
\hline
\end{tabular}

* = Significant at the 90 percent level.

$* *$ = Significant at the 95 percent level.

$* * *=$ Significant at the 99 percent level.

Notes: We estimate the century differences in the response of county farm output value to short-term weather conditions. The short-term weather conditions are measured by the annual mean temperature $(T)$ and accumulated precipitation $(P)$ in the census year. The specification in each regression is the same as in Table 2. The standard errors of regression coefficients, reported in parentheses, are clustered on county.

Sources: Authors' calculations. 
The two weather variables are frequently interrelated. For example, southern counties' climates are characterized not only by high temperatures but also by wet and humid weather. The impact of one weather component on farm value can be compounded by another. We consider this issue in Panel $\mathrm{C}$ by running a regression for county farm value on decadal temperature and precipitation and the demeaned interaction of the two weather variables. Other specifications are the same as those used in Panels A and B across the columns. In terms of the coefficients in column (4), which uses stricter controls, the interaction effect and its change over the century appear small or less significant.

To gain a better sense of the implications of the estimated coefficients, we imagine two counties with different levels of annual mean temperature: $55.4^{\circ} \mathrm{F}$ for the average county and $62.5^{\circ} \mathrm{F}$ for a hot county, which is one standard deviation higher than the mean temperature. ${ }^{10}$ We assume that the levels of precipitation and other agricultural conditions are identical between counties and across centuries. Then, using the coefficient of $T \times D_{19}$ in column (4) of Panel C, the cross-century difference in farm value as a ratio (in other words, the level of farm value in the late twentieth century relative to that in the late nineteenth century) is estimated to be 13.7 for the average county and 19.1 for the hot county. ${ }^{11}$ Because there is little difference in county farm value by local temperature today, this simulation suggests that adaptation occurred more rapidly in hotter areas over time. Similarly, using the coefficient of $P \times D_{19}$ in column (4) of Panel $C$, the cross-century difference in farm value as a ratio is estimated to be 1.6 for a county with average annual precipitation (41.4 inches) and 1.9 for a wet county with 51.9 inches of annual precipitation, which is one standard deviation higher than the average precipitation. The rate of adaptation seems to be smaller than is that of temperature. However, it still suggests that adaptation to precipitation was evident in wetter areas.

\section{Short-Term Weather Fluctuations and Farm Output Value}

In this subsection, we employ an alternative measure of farm productivity: the value of county farm output. This measures how the growth

\footnotetext{
${ }^{10}$ We report the summary statistics of weather variables in Appendix Table 1 in Appendix 1.

${ }^{11}$ Suppose that $F V_{19 \mathrm{C}}$ and $F V_{20 \mathrm{C}}$ denote average farm value in a county in the late nineteenth and late twentieth centuries, respectively. Accordingly, the cross-century difference in farm value as a ratio $\left(F V_{20 \mathrm{C}} \div F V_{19 \mathrm{C}}\right)$ in a county with specific long-term weather condition is measured by $\exp \left(-\beta_{T} \cdot T\right)$ regarding temperature $(T)$ or $\exp \left(-\beta_{P} \cdot P\right)$ regarding precipitation $(P)$. The interaction between temperature and precipitation increases the estimated magnitude of the historical changes by a small amount, as discussed in the text.
} 
of crops is affected by local weather conditions. ${ }^{12}$ Unfortunately, farm output value is not available in the census years of 1910, 1920, and 1930. Thus, we use the panel regression described by equation (2), which compares 1870-1900 to 1970-2000, and to which we add state-by-year and county fixed effects. In addition, agricultural production depends more on weather conditions in the year of production (in other words, short-term weather conditions) than decadal weather conditions. Thus, we estimated the short-term weather variables as average temperature and accumulated precipitation in one year before each census year. ${ }^{13}$

In Table 2, we examine the marginal effect of short-term weather conditions on county farm output value and its change over the centuries. The regression model and specification in each cell are the same as those used in Table 1. The main findings are that hot and rainy shortterm weather was less favorable for producing agricultural output in the late nineteenth century than it was in the late twentieth century and that the adaptation of farm output value to weather occurred more-or-less steadily across decades..$^{14}$ Moreover, the magnitude of the adaptation to the weather (in other words, the difference in marginal effect across the centuries) is similar to what we estimated using farm value and long-term weather variables in the previous subsection. Again, these results suggest that a forecast of the impact of climate change during one century made with data from the prior century would be problematic.

\section{Robustness}

In Table 3, we test the significance of the agricultural adaptation with alternative weather variables and by scale of agriculture. First, we employ alternative weather variables in columns (2) and (3). Crops are cultivated even in winter in some regions, and most of the precipitation comes from the rainy winter season in others. However, weather conditions in winter

${ }^{12}$ Farm output value has been used in various recent studies (for example, Deschênes and Greenstone 2007; Schlenker and Roberts 2009). However, those studies utilize daily temperature variables and farm profits, neither of which are available for historical periods.

${ }^{13}$ For example, the 1870 agricultural census surveyed farm output that were produced during the year ending in June 1870 . We assume that farm output surveyed in 1870 was largely affected by weather condition in 1869 . We conducted the analysis noted earlier using weather variable estimated for the census year (i.e., 1870), but the result did not change much.

${ }^{14}$ To determine whether this result is correlated with the effect of weather in other years around the census year, we conducted additional regressions by adding short-term weather variables measured in the periods one year after and before the census year. It is found that the cross-century change in the response to weather is strongly estimated only for the current-year weather variables and that the estimated effect of weather in adjacent years is non-significant and negligible. 
TABLE 3

ALTERNATIVE WEATHER VARIABLES AND INFLUENCE OF LARGE-SCALE AGRICULTURAL COUNTIES

\begin{tabular}{|c|c|c|c|c|c|c|}
\hline \multirow[b]{4}{*}{ Key Variable } & (1) & $(2)$ & (3) & (4) & $(5)$ & $(6)$ \\
\hline & \multirow[b]{3}{*}{ Baseline } & \multicolumn{2}{|c|}{ Alternative Weather Variables } & \multicolumn{3}{|c|}{ Influence of Large-Scale Agricultural Counties } \\
\hline & & \multirow[b]{2}{*}{$\begin{array}{c}\text { March-to-October } \\
\text { Average }\end{array}$} & \multirow[b]{2}{*}{$\begin{array}{l}\text { Average Weather } \\
\text { over 1860-2000 }\end{array}$} & \multirow{2}{*}{$\begin{array}{c}\text { Regression Weight }= \\
\text { The ratio of Farmland Acres out } \\
\text { of Total County Area }\end{array}$} & \multicolumn{2}{|c|}{$\begin{array}{l}\text { Average Ratio of Farmland out of Total County Area: } \\
\qquad 0.54 \text { in } 1870,0.48 \text { in } 2000\end{array}$} \\
\hline & & & & & $\begin{array}{l}\text { Counties above the Cutoff } \\
\text { Value in both } 1870 \text { and } 2000\end{array}$ & $\begin{array}{l}\text { Counties Below the Cutoff } \\
\text { Value in both } 1870 \text { and } 2000\end{array}$ \\
\hline \multicolumn{7}{|c|}{ Panel A: $Y=$ farm value, $T=$ decadal temperature } \\
\hline$T \times D_{19}$ & $\begin{array}{l}-0.0470^{* * *} \\
(0.0056)\end{array}$ & $\begin{array}{l}-0.0505^{* * *} \\
(0.0067)\end{array}$ & $\begin{array}{c}-0.0495 * * * \\
(0.0053)\end{array}$ & $\begin{array}{c}-0.0476 * * * \\
(0.0050)\end{array}$ & $\begin{array}{c}-0.0525 * * * \\
(0.0070)\end{array}$ & $\begin{array}{l}-0.0521 * * * \\
(0.0132)\end{array}$ \\
\hline \multicolumn{7}{|c|}{ Panel B: $Y=$ farm value, $P=$ decadal precipitation } \\
\hline$P \times D_{19}$ & $\begin{array}{c}-0.0162 * * * \\
(0.0030)\end{array}$ & $\begin{array}{c}-0.0202 * * * \\
(0.0054)\end{array}$ & $\begin{array}{c}-0.0176^{* * *} \\
(0.0033)\end{array}$ & $\begin{array}{c}-0.0149 * * * \\
(0.0027)\end{array}$ & $\begin{array}{c}-0.0397 * * * \\
(0.0048)\end{array}$ & $\begin{array}{c}-0.0191 * * * \\
(0.0047)\end{array}$ \\
\hline \multicolumn{7}{|c|}{ Panel C: $Y=$ farm output value, $T=$ annual temperature } \\
\hline$T \times D_{19}$ & $\begin{array}{c}-0.0416^{* * *} \\
(0.0086)\end{array}$ & $\begin{array}{c}-0.0381 * * * \\
(0.0098)\end{array}$ & & $\begin{array}{c}-0.0330 * * * \\
(0.0075)\end{array}$ & $\begin{array}{l}-0.0020 \\
(0.0112)\end{array}$ & $\begin{array}{c}-0.0710^{* * *} \\
(0.0175)\end{array}$ \\
\hline \multicolumn{7}{|c|}{ Panel D: $Y=$ farm output value, $P=$ annual precipitation } \\
\hline$P \times D_{19}$ & $\begin{array}{l}-0.0114 * * * \\
(0.0031)\end{array}$ & $\begin{array}{l}-0.0151 * * * \\
(0.0033)\end{array}$ & & $\begin{array}{c}-0.0070 * * * \\
(0.0025)\end{array}$ & $\begin{array}{l}-0.0055^{* *} \\
(0.0028)\end{array}$ & $\begin{array}{c}-0.0137 * * \\
(0.0058)\end{array}$ \\
\hline Observations & 16,864 & 16,864 & 16,864 & 16,864 & 4,360 & 4,336 \\
\hline
\end{tabular}

$*$ Significant at the 90 percent level.

** = Significant at the 95 percent level.

*** = Significant at the 99 percent level.

Notes: We estimate the level of agricultural adaptation to weather, which we examined in Tables 1 and 2, using alternative weather variables, specification, or county groups, as explained in the head of columns. Panels A and B estimate the relationship between county farm value and decadal weather variables, and Panels C and D regard county farm output value and annual weather variables. The specification of each regression is the same as for column (4) of Panel A or B in Tables 1 and 2, where we adopted the baseline results in this table. We report only the coefficient of weather variables interacting with the dummy variable indicating the census years in the nineteenth century. Because column (3) uses the average weather variables calculated for the whole time horizon, the estimation of short-term weather variables in Panels C and D is unfeasible. The regression weights, except in column (4), are the inverse value of the decadal, annual or centurial weather estimates' standard errors, which is calculated from the Kriging estimation. The standard errors of regression coefficients, reported in parentheses, are clustered on county. Sources: Authors' calculations. 
are less significant for agriculture in many regions. To reflect this fact, we control for annual and decadal average weather variables calculated only for the months of March to October in column (2). On the other hand, we employ average weather variables calculated over the whole time horizon (1860-2000) in column (3) to eliminate the bias caused by the noisy nature of temperature and precipitation. The estimation results in both models are similar to those of the baseline estimation in column (1).

Second, the extent of agriculture varies across counties and decades. More agricultural counties can be more active in adapting to weather than small-scale agricultural counties. Thus, the relationship between agricultural outcomes and weather could be influenced by counties with largescale agriculture. To test this possibility, we conduct three additional analyses. In column (4), we run weighted regressions with the ratio of farmland to total county area in each census year as regression weights. This up-weights counties that are more agricultural. The result is similar to that of the baseline estimation. Alternatively, we restrict the regressions to counties with large-scale agriculture both in 1870 and 2000 in column (5) and those with small-scale agriculture in both census years in column (6). In both columns, we utilize the average ratio of county farmland in each census year to divide large- from small-scale agriculture. In columns (5) and (6), the adaptation is substantially estimated not only for large-scale agricultural counties but also small-scale ones. In particular, the adaptation in the relationship between annual temperature and farm output value is estimated more substantially for small-scale agricultural counties, suggesting that the adaptation to weather widely occurred across the broad scale of agriculture.

Third, some may argue that a substantial response to extreme weather conditions would be to not settle the regions with extreme conditions. In this case, many unsettled areas, particularly in earlier sample years, could skew the analysis by resulting in high farm value per farmland acre even though county land was not valuable on average. Then, the value per farmland acre could fall over time as more places become tolerable due to technological adaptation. We may not be able to completely test and reflect this possibility. Considering data limitations, one way of testing is to employ farm value or output value per county area rather than those per farmland acre.

The results of using those alternative dependent variables are reported in column (2) of Table 4 . The coefficients of precipitation interacted with the nineteenth century dummy are estimated to be somewhat smaller than those of the baseline estimation in Panels B and D. This may suggest that 
TABLE 4

ALTERNATIVE MEASURES OF FARM PRODUCTIVITY

\begin{tabular}{|c|c|c|c|c|}
\hline & $(1)$ & (2) & (3) & (4) \\
\hline & & & \multicolumn{2}{|c|}{$\begin{array}{l}\text { Double Counting Issue } \\
\text { of Farm Output Value }\end{array}$} \\
\hline Key Variable & Baseline & $\begin{array}{l}\text { Using Per-County- } \\
\text { Acre Values }\end{array}$ & $\begin{array}{l}\text { Discounting the } \\
\text { Production of } \\
\text { Corn and Hay }\end{array}$ & $\begin{array}{l}\text { Discounting Total } \\
\text { Farm Output Value }\end{array}$ \\
\hline
\end{tabular}

Panel A: $Y=$ farm value, $T=$ decadal temperature

\begin{tabular}{ccc}
\hline$T \times D_{19}$ & $-0.0470^{* * *}$ & $-0.0513 * * *$ \\
& $(0.0056)$ & $(0.0052)$ \\
\hline
\end{tabular}

Panel B: $Y=$ farm value, $P=$ decadal precipitation

\begin{tabular}{ccc}
\hline$P \times D_{19}$ & $-0.0162 * * *$ & $-0.0067 * *$ \\
& $(0.0030)$ & $(0.0030)$
\end{tabular}

Panel C: $Y=$ farm output value, $T=$ annual temperature

\begin{tabular}{ccccc}
\hline$T \times D_{19}$ & $-0.0416^{* * *}$ & $-0.0375^{* * *}$ & $-0.0402 * * *$ & $-0.0384 * * *$ \\
& $(0.0086)$ & $(0.0078)$ & $(0.0100)$ & $(0.0097)$ \\
\hline
\end{tabular}

Panel D: $Y=$ farm output value, $P=$ annual precipitation

\begin{tabular}{lcccc}
\hline$P \times D_{19}$ & $-0.0114 * * *$ & -0.0033 & $-0.0067 * *$ & $-0.0060^{*}$ \\
& $(0.0031)$ & $(0.0026)$ & $(0.0032)$ & $(0.0033)$ \\
\hline Observations & 16,864 & 16,864 & 10,432 & 10,459 \\
\hline
\end{tabular}

$*=$ Significant at the 90 percent level.

** = Significant at the 95 percent level.

*** = Significant at the 99 percent level.

Notes: In this table, we employ alternative measures of county farm value and output value. Column (2) uses county farm value or output value per county acre rather than per county farmland acre. In column (3), to reflect the potential double counting of farm output value, we re-calculated county farm output value by excluding 50 percent of corn production and all hay production for nineteenth-century censuses and 15 percent of corn production and all hay production for twentieth-century censuses. We discounted crop values by 10 percent in column (4). Columns (3) and (4) use only the data for 1870, 1900, 1970, and 2000 due to data limitation. Other specification of estimation is the same as that of Table 3 . The regression weights are the inverse value of the decadal, annual or centurial weather estimates' standard errors, which is calculated from the Kriging estimation. The standard errors of regression coefficients, reported in parentheses, are clustered on county.

Sources: Authors' calculations.

much farmland in the late nineteenth century was unsettled or not valuable. If the pattern was more frequent in dry counties (more land-improved) than in wet counties (less land-improved), the nineteenth-century slope of agricultural outcomes per county acre against average precipitation would be flatter than as seen in Figure 1; however, this pattern seems to be less likely in terms of temperature. The estimated coefficients of temperature in column (2) are similar to those of the baseline. 
Finally, there could be a measurement error problem due to double counting in farm output value. Regarding this issue, the 1880 census volume states the following (U.S. Bureau of Census 1883, p. 26):

A large part of the corn, and a still greater portion of the hay, returned in the census are consumed for the purpose of the annual product of animal food. If the values of both the vegetable and the animal products are counted, there will be duplication to this extent...An investigation of the distribution and consumption of the corn crop of 1882, undertaken by the statistician of the department of agriculture, made the consumption for free of cattle and swine, for flesh-making or fattening purposes, 46.6 percent of the total crop. ${ }^{15}$

The double-counting problem can be partially addressed by constructing separate crop and livestock output measures. However, it seems to be difficult to reflect the double counting problem in our estimation systematically. Calculating a county's total value of farm output was based on farmers' reports in the census. Because farmers generally report only the value of their ultimate product, we are not able to calculate the value of duplications. Handling the double-counting problem becomes more complex at the county level because feed crops produced in a county are not always consumed in the same county.

In addition, as farms are less specialized, the double-counting problem is more serious; thus, the problem would be greater for data in the nineteenth and early twentieth centuries (Gardner 2009). As discussed earlier, about 46.6 percent of corn production was estimated as the proportion of double counting; the ratio declined to 14.2 percent in the 1982 agricultural census and to 13.9 percent in the 1992 census. ${ }^{16}$

We can partially test how double counting may affect our estimation. First, we recalculated county farm output values reflecting the potential double-counting problem. ${ }^{17}$ We assume that 50 percent of corn production was used for feeding livestock in the late nineteenth century, and 15 percent in the late twentieth century, following the discussion earlier. We also assume that hay would be used only for feeding livestock. Second, we discount county crop value by 10 percent in calculating total farm output value. ${ }^{18}$ Columns (3) and (4) in Table 4 employ recalculated farm

\footnotetext{
${ }^{15}$ The issue is also discussed in Olmstead and Rhode (2008, pp. 94-5, 265-82).

${ }^{16}$ The ratio was estimated using information on farmland acres for corn production by purpose (grain vs. silage) in the census records.

${ }^{17}$ We are grateful to Paul Rhode for suggesting this strategy.

${ }^{18}$ At the aggregate level, the ratio of feed crops out of total value of crop production is estimated at around 10 percent throughout the twentieth century (calculated from Series Da1067 and Da1069 in Volume 4 of Carter et al. [2006]).
} 
output values as dependent variables. Their results are comparable to the baseline results, even though only data for 1870, 1900, 1970, and 2000 were used due to data limitations.

\section{EARLY-LIFE WEATHER AND ADULT INCOME}

\section{Significance of Weather Conditions in Early Life}

Many studies have revealed that climate and climate change affect activities and the lifetime health of individuals by causing malnutrition from crop failure (Ó Gráda 2007), spreading infectious diseases (Lafferty 2009; Bleakley 2007; Hong 2007, 2011, 2013), distorting health conditions over the course of life (WHO, WMO, and UNEP 2003; Patz et al. 2005), changing ecological systems (Thomas et al. 2003), and so on. They generally predict that the overall impact of climate change like global warming would be detrimental to human life. From an economic perspective, the channels noted earlier are closely related to the reduction of individuals' economic productivity. ${ }^{19}$

Recently, Deschênes, Greenstone, and Jonathan Guryan (2009) demonstrated that extreme temperature in utero can increase the risk of having babies with low birth weights (see also Murray et al. 2000; Lawlor, Leon, and Smith 2005). Although further evidence is required, they suggest that this can be caused by the association between weather in utero and fetal nutrient intake and stress. The relationship between weather in utero and birth outcome is significant because adverse birth outcomes can affect life-time human capital accumulation (for example, schooling, disability, adult income), as suggested by the fetal origins hypothesis, which has been supported by many studies (Barker 1994; Almond 2006; Black, Devereux, and Salvanes 2007). In addition, it has been reported consistently that maternal exposure to infectious diseases promoted by weather - most notably malaria - increases the probability of having babies with low birth weights (Desai et al. 2007) and that earlylife exposure to malaria can reduce cognitive ability and thus the acquisition of human capital (Holding and Snow 2001; Sachs and Malaney 2002; Bleakley 2010; Barreca 2010; Hong 2011).

\footnotetext{
${ }^{19}$ For example, the adverse health impacts of hot and wet climates can reduce individuals' work productivity and thus their income. Changes in economic sectors due to climate change can affect industrial structures and labor markets and therefore wages.
} 


\section{Cross-Sectional Evidence}

In consideration of this mechanism, our study focuses on the significance of early-life weather for later economic outcomes and relevant changes throughout U.S. history. We first look for cross-sectional evidence demonstrating the relationship between weather and adult occupational income from a longer-term perspective using simple bivariate analysis. The adult income variable used is the average occupational income score by stateof-birth cohorts aggregated from the 1880 and 1900 to 1990 IPUMS. We limited individuals to white males born from 1860 to 1960 and observed during working ages (20 to 65) in the Census IPUMS of 1880 to 1990. Using the county weather variables imputed by the Kriging interpolation technique, we construct the 1860-2000 average of annual mean temperatures and annual accumulated precipitation by state. The weather variables represent the overall weather conditions that each cohort might have experienced in early life rather than at a specific point in time.

In Figure 3, we plot average adult occupational income score against long-term average weather variables in the state of birth by two cohort groups: 1860 to 1899 and 1931 to 1960 . The figure shows that adult income among the cohort born before 1900 decreases with increasing temperature and precipitation in the state of birth. ${ }^{20}$ In other words, people who were born or had spent their early lives in hotter and wetter states attained lower paying occupations, on average, later in life. However, this relationship almost completely disappears for the cohort born after 1930; there is little difference in adult occupational income by early-life average weather conditions. (The $y$-axis scale is the same across cohorts for the same outcome; note the compression of the points for the later cohorts.) This suggests the possibility that technological adaptation took place throughout the early twentieth century, mitigating the adverse effects of high temperature and rainfall on individuals' economic productivity.

\section{The Diminishing Effect of Short-Term Weather Fluctuations}

In addition to the historical change in the relationship between longterm weather in early life and adult income, we find instability in the

\footnotetext{
${ }^{20}$ The negative linear relationship observed in Figure 3 is estimated as being statistically significant for the nineteenth-century data. The estimated coefficients (standard errors) of OLS regressions, which use only the weather variable and constant term as controls, are -0.0094 (0.0020) for temperature and $-0.0024(0.0012)$ for precipitation.
} 

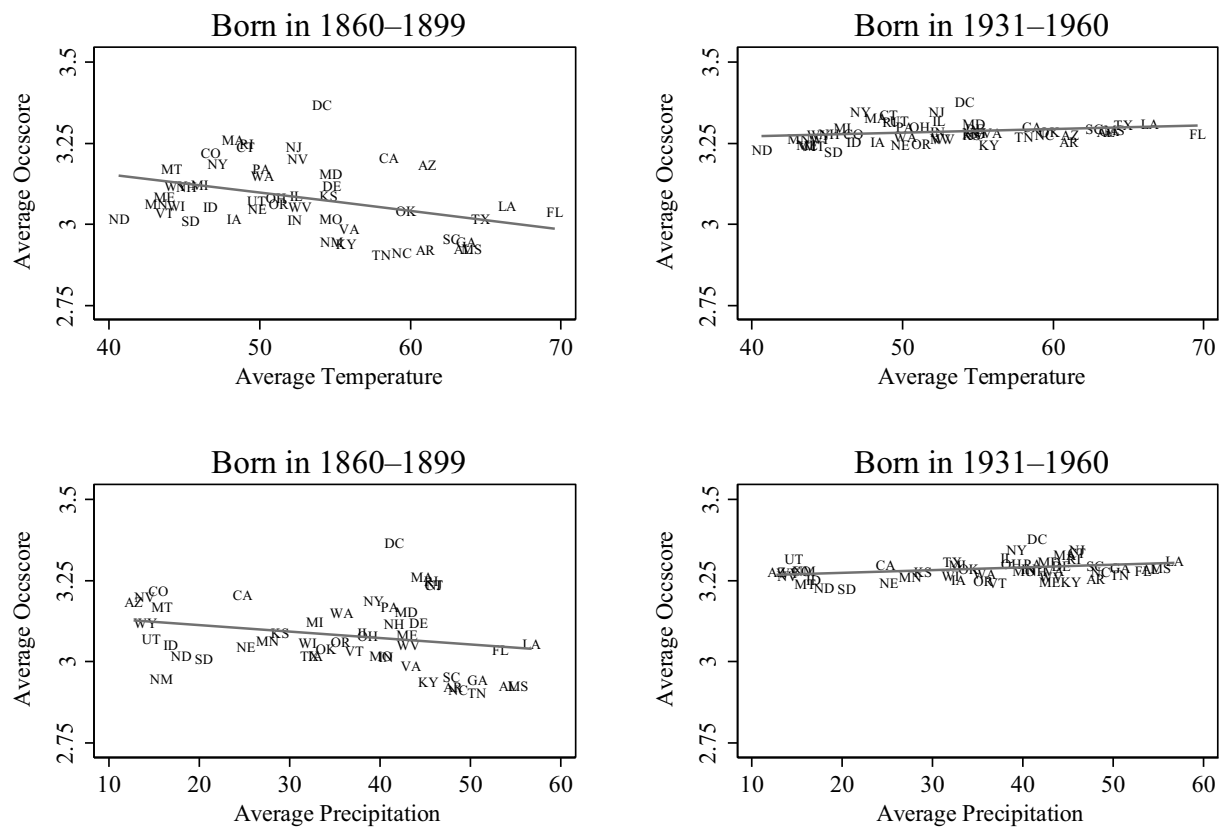

FIGURE 3

THE RELATION BETWEEN AVERAGE WEATHER CONDITIONS IN EARLY LIFE AND ADULT INCOME BY TWO COHORTS

Notes: This figure plots a proxy of adult income against the state-of-birth average temperature and precipitation for earlier- and later-born cohorts in the United States. We use the 1860-2000 average of annual mean temperature and annual accumulated precipitation by state. A cohort is defined by year of birth and state of birth. Data on native adult white males are drawn from the 1880 and $1900-1990$ IPUMS, which span the years of birth 1860-1960. The outcome variable is the average occupational income score, transformed into natural logarithms. Cohorts are grouped into those born before 1900 (in the left plots) and those born after 1930 (in the right plots). The $\mathrm{x}$-axis is the state-of-birth average temperature in the upper plots or precipitation in the bottom plots. The y-axis in each plot refers to the cohort group's average income score. State abbreviations are used to denote the position of each point. The solid line is the best-fit regression line between the points.

Sources: Authors' calculations based on IPUMS dataset (Ruggles et al. 2015) and Kriginginterpolated weather variables.

effect of short-term weather fluctuations around the year of birth on adult income using fixed-effects models. The use of long-term average weather not only captures the effect of weather around the time of birth but also measures the accumulated or lifetime effect of weather if a large proportion of each state-of-birth cohort has lived in the same state for a considerable amount of time. The use of short-term weather variables can more clearly identify the effect of early-life weather on adult income.

In the following estimation model, we search for the specific point in time around birth at which weather conditions have significant effects on adult income by running a regression predicting the cohort average 

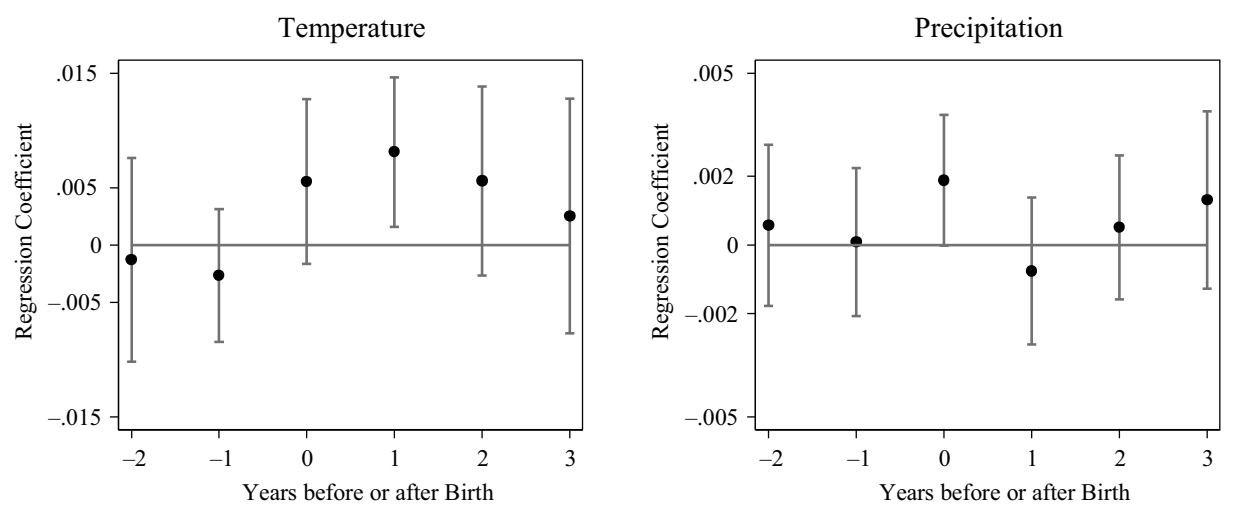

FIGURE 4

SHORT-TERM WEATHER FLUCTUATIONS AROUND YEAR OF BIRTH AND OCCUPATIONAL INCOME IN ADULTHOOD

Notes: This figure summarizes regressions of cohort outcome on early-life weather conditions, per equation (3) in the text. Short-term weather variable is annual mean temperature or accumulated precipitation in each state. A cohort is defined by year of birth and state of birth. Data on native adult white males are drawn from U.S. censuses of 1880 and 1900-1990, which span the years of birth 1860-1960. The outcome variable is, at the cohort level, the occupational income score transformed into natural logarithms. The $x$-axis in each plot refers to the calendar year minus the year of birth. The $y$-axis in each plot displays the estimated regression coefficient on the interaction of the indicated weather variable (temperature or precipitation) and a dummy for the calendar year minus year of birth. The error bars reflect 95 percent confidence intervals for each coefficient.

Sources: Authors' calculations.

occupational income score from annual mean temperature and accumulated precipitation at the year of birth, at the three years after birth, and at two years before birth, per equation (3):

$$
Y_{j k t}=\alpha+\sum_{l=-2}^{3}\left(\beta_{l} T_{j, k+l}+\gamma_{l} P_{j, k+l}\right)+\delta_{j t}+\delta_{k t}+\varepsilon_{j k t},
$$

where the subscripts $j, k$, and $t$ denote state of birth, year of birth, and census year, respectively.

The regression is conducted for cohort samples defined by state of birth and year of birth from 1860 to 1960 . The model also contains dummies for each cell of state of birth times census year $\left(\delta_{j t}\right)$, and dummies for each cell of year of birth times census year $\left(\delta_{k t}\right)$. These fixed effects will capture omitted and unmeasured characteristics in state of birth, year of birth, and census year that might commonly affect those in a given cohort.

We summarize the key results of the regression for equation (3) in Figure 4. The $y$ axis in each plot displays the estimated regression coefficient on the interaction of the indicated weather variable and a dummy for the calendar year minus year of birth—thus, $\beta_{l}$ or $\gamma_{l}$; the $x$ axis in each 
plot denotes the calendar year minus the year of birth. The error bars reflect 95 percent confidence intervals for each coefficient.

The main finding is that adult occupational income scores have been highly associated with cross-year weather fluctuations for specific years in early life. Weather conditions before birth do not have meaningful effects. The year in which temperature has the most substantial, significant effect on adult occupational income is one year after birth; the effect declines over the next two years. The effect of precipitation is most substantial at the year of birth and then becomes non-significant. ${ }^{21}$

Because the state-of-birth fixed effects capture state-specific climatic characteristics, the earlier estimation measures the effect of within-state across-year variation in weather conditions around birth. Although many studies suggest a negative effect of hot and wet weather in utero on birth outcomes, some studies have found a positive association between hot/ wet weather in early life and conditions at birth through improvement in maternal nutritional status (Costa 2004). From the perspective of the fetal origins hypothesis, the positive effect of temperature on birth outcomes can lead to a higher level of human capital accumulation and thus adult income (Maccini and Yang 2009; Barreca 2010).

Following this line of research, it is interesting that meaningful associations among weather, nutrition in utero, birth outcome, and later outcome are frequently found in studies of historical experiences and developing countries. This association might be attenuated in modern, developed countries by a sufficient year-round food supply, public programs, and technological adaptation. This suggests that the coefficients presented in Figure 4 may vary across cohorts. To investigate this possibility, we look at how the effect of short-term weather fluctuations on adult income has changed across cohorts.

We measure this long-term pattern by estimating equation (3) with a 40 -year-wide moving window. The sample for each regression includes cohorts born 20 years before and after the target year; the target years are thus between 1880 and 1940. Figure 5 presents the estimated regression coefficient for the interaction between the indicated weather variable and a dummy for the year chosen according to the results in Figure 4 (in other words, one year after the year of birth for temperature and the year of birth for precipitation). We also add the 95 percent confidence intervals for each coefficient.

\footnotetext{
${ }^{21}$ These results for short-term weather have implications beyond the findings from the crosssectional analysis in the previous subsection, which suggested a negative correlation between long-term weather conditions for cohorts born before 1900. The use of different weather variables and fixed-effect estimation might be relevant to the difference.
} 
Temperature
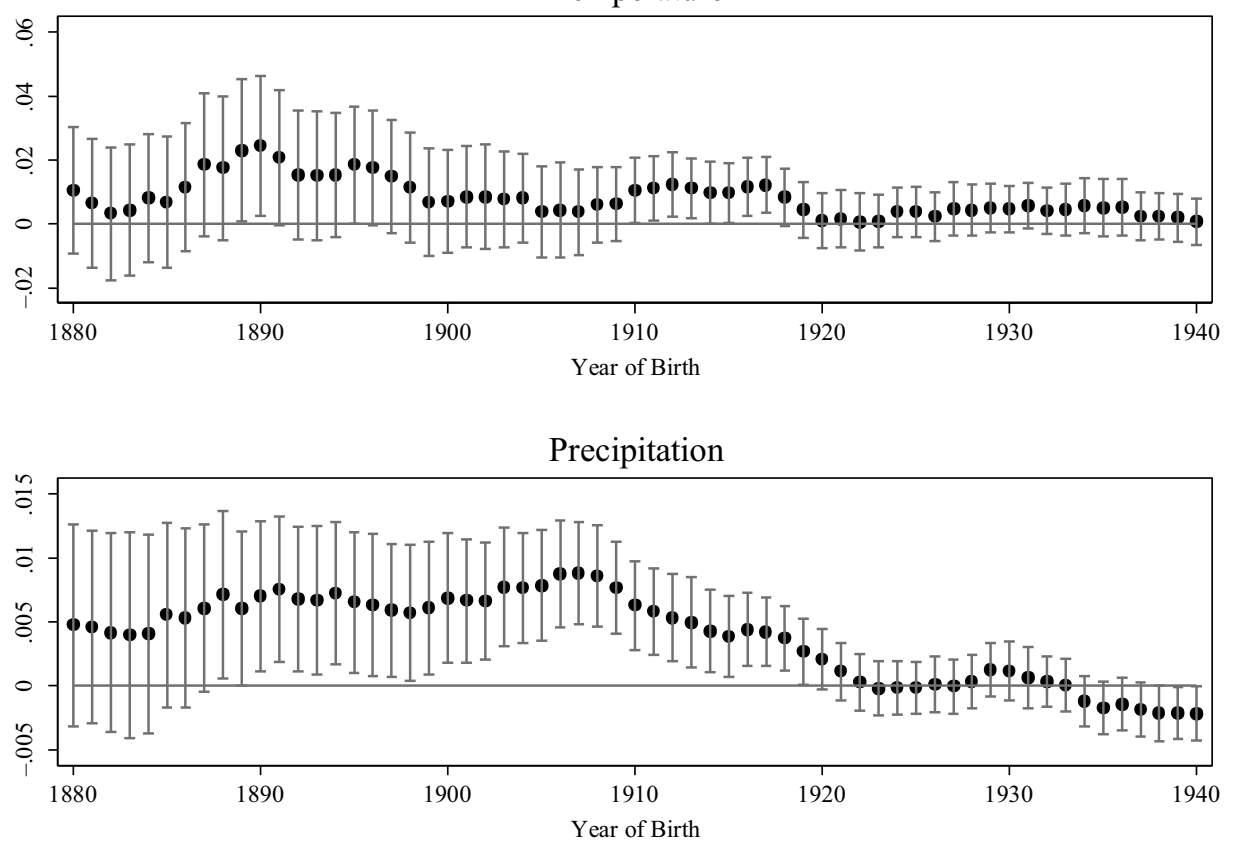

FIGURE 5

THE DIMINISHING EFFECTS OF EARLY-LIFE WEATHER FLUCTUATIONS ON OCCUPATIONAL INCOME IN ADULTHOOD

Notes: We estimated equation (3) for a 40 -year-wide moving window so that the sample for each regression includes white-male cohorts born 20 years before and after the target year. Regarding weather variables, we only control for temperature in the period one year after birth and precipitation at the year of birth according to the results in Figure 4. The $x$-axis in each plot refers to the average year of birth for cohort samples used. The $y$-axis in each plot displays the estimated regression coefficient on the interaction of the indicated weather variable (temperature or precipitation) and a dummy for the year chosen as explained above. The error bars reflect 95 percent confidence intervals for each coefficient.

Sources: Authors' calculations.

The result shows that the effect of short-term weather fluctuations diminished across cohorts. The effect is generally positive among cohorts born in the second half of the nineteenth century, and its across-cohort variation is substantial. However, as the target year approaches 1910 to 1920 , the magnitude, significance, and across-cohort variation of the effect attenuate. Weather in early life became less relevant to adult income.

In the upper panel of Figure 5, the estimated coefficient of temperature for 1890 suggests that a one-degree increase in annual mean temperature at age 1 (from its state average) resulted in a 2.4 percent increase in adult income (measured by occupational income score) during the 1870 to 
1910 period. The coefficient for 1930 implies that a one-degree increase in annual mean temperature led to a 0.47 percent increase in adult income during the 1910 to 1950 period, but the result is statistically insignificant. Similarly, in the lower panel of Figure 5, the coefficient of precipitation for 1890 suggests that a one-inch increase in annual accumulated precipitation at the year of birth (from its state average) resulted in a 0.7 percent increase in adult income during the 1870 to 1910 period. That of 1930 implies that a one-inch increase in precipitation led to a 0.12 percent increase in adult income during the 1910 to 1950 period, but the result is statistically insignificant.

The pattern of attenuation over time in Figure 5 is similar to what we observe in the cross-sectional analysis using long-term weather variables, although the role of weather in early life is estimated differently between the two analyses. Moreover, it is worthwhile to remind that the diminishing effect of weather was similarly found in the analysis of farm productivity in the previous section. The findings thus far suggest that adaptation to weather significantly occurred throughout the early twentieth century, not only in the agricultural sector but also at the individual level. Once again, we see different coefficients estimated over the course of U.S. history. In this case, the more dated coefficients drastically overstate the impact of climate and human capital.

\section{CONCLUDING REMARKS}

This study's findings suggest difficulties in forecasting the effects of climate change with either hedonic or fixed-effect models, particularly if they are estimated within a relatively narrow time window. An advantage of the cross-sectional (in other words, hedonic) comparison method is that the observed differences across areas partially reflect adaptation. However, a weakness in this approach is that such adaptation is observable only within the scope of currently available technology; this is clearly an incomplete account of adaptation. Stated otherwise, imagine being in 1910 and tasked with forecasting the effects of a warmer and wetter climate. A projection based on U.S. historical experience up to that point would vastly overstate the (negative) response by failing to account for the subsequent evolution of technology, which improved productivity in warm and wet areas. On the other hand, an advertised benefit of panel/fixed-effect methods is that they provide an upper bound to the magnitude of the response to climate change. This argument rests on the so-called "Le Chatelier principle": more adaptation is possible 
in the long run; thus, sensitivity to a change in weather should lessen at longer time periods. Nevertheless, the scope of adaptation has not been sufficiently examined in existing studies, most of which examine the second half of the twentieth century.

The main contribution and novelty of this study is its extension of the time window to the past century-and-a-half, throughout which humankind has experienced substantial adaptation to the weather. This allows us to quantify the level of adaptation from various aspects (in other words, cross-sectional and panel/fixed approach, agricultural and individual productivity, and short-term and long-term adaptation). The main finding is that in the U.S. farm value and farm output value substantially declined as the region became hotter and wetter in the late nineteenth century, but the adverse effects have been almost completely attenuated in recent decades. The lesson from U.S. history is that human efforts to enhance agricultural technologies and improve ecological environments have been effective in overcoming the adverse effects of hotter and wetter weather. Although it is difficult to forecast the effects of climate change, our study suggests that the consideration of possible technological adaptations and a longer-term perspective are crucial in the forecasting. ${ }^{22} \mathrm{At}$ the very least, we note that today's relationships between weather or climate and economic outcomes may be poor guides to the future forms of such relationships, inasmuch as these relationships have been unstable over historical time scales.

\section{Appendix 1: Weather Variable}

\section{Raw Data from Weather Stations}

Monthly mean temperature and accumulated precipitation are obtained from two historical sources: the records of the Nineteenth-Century U.S. Climate Data Set Project developed by the National Climate Data Center and the Long-Term Daily and Monthly Climate Records from the Stations across the Contiguous United States provided by the

\footnotetext{
${ }^{22}$ A question that emerges from this study is "How much change can we expect in the response of economic variables to weather climate going forward?" One could imagine using the acrosscentury differences in parameter estimates to calibrate this drift, but this is problematic in a number of ways. First, it could be argued that the change across the twentieth century is a single realization and thus not useful for calibrating a distribution of parameter drift without strong prior information. Second, there may be little reason to believe that the instability of parameters over time is itself governed by a stable process. We hope to see a great deal of technical progress specifically directed towards adapting to the climate in an expectation of its change.
} 
U.S. Historical Climatology Network. The former dataset covers from 1822 to 1900 and includes 4,056 individual weather stations with different names. However, not all the stations existed throughout the nineteenth century. The number of weather stations was under 100 prior to 1854 and increased to about 400 in the $1860 \mathrm{~s}$, and then to about 1,000 after the $1880 \mathrm{~s}$. The later dataset has been utilized to obtain monthly weather information covering 1901 to 2000 . The number of weather stations in the dataset is 1,221 . Each weather station existed over most years of the twentieth century, so that each year's number of stations is over 1,000 . Two datasets include information on weather stations' latitude and longitude, which is used to locate them on the map.

\section{Spatial Averaging ("Kriging”)}

A Kriging technique is used to interpolate monthly weather variables for the counties whose weather records are not found in the two sources noted earlier. The method is based on a linear least squares estimation algorithm, which minimizes the variance of the prediction error. Thus, a Kriging estimator is a linear combination of the values at nearby locations; the distance between neighboring points is generally employed as weights. In this study, the maximum distance between points is set as 200 miles. A sufficient number of weather stations within a 200-mile radius of the target location are required to obtain a reliable estimation result. The sizes of weather stations in the years prior to 1860 were considered insufficient; those years were thus dropped from the analysis.

We tested whether the Kriging estimation is valid by comparing estimated weather variables with actual ones. For the test, we selected 5 percent random counties out of counties with weather stations between 1890 and 1899 (60 out of 1,200 counties). We conducted the Kriging method to estimate monthly temperature and precipitation variables across counties, dropping the variables of 60 randomly selected counties. In Appendix Figure 1, we compare estimated values with actual values in terms of annual (1899) and decadal (1890-1899) weather variables for the 60 counties. Scatter plots are located around 45-degree lines. We also tested a null hypothesis that actual and estimated variables are statistically the same. The p-value for the test is reported in the figure, and the hypothesis is accepted in all cases.

\section{Estimation of Weather Variables by County}

To estimate the county-level monthly mean temperature and accumulated precipitation from 1860 to 2000, the geographical center of each county was used as the target location in the Kriging estimation, and the actual weather information of weather stations within a 200-mile buffer around the target location was utilized. The countylevel decadal (long-term) or annual (short-term) average temperature is calculated by averaging monthly estimated results over the specified periods. The decadal precipitation is the average value of annual accumulated precipitation for the 10 years prior to each census year; the annual precipitation is calculated by summing up monthly precipitation over the year. Appendix Table 1 presents the mean and standard error of the estimated long- and short-term weather variables throughout the sample periods. 

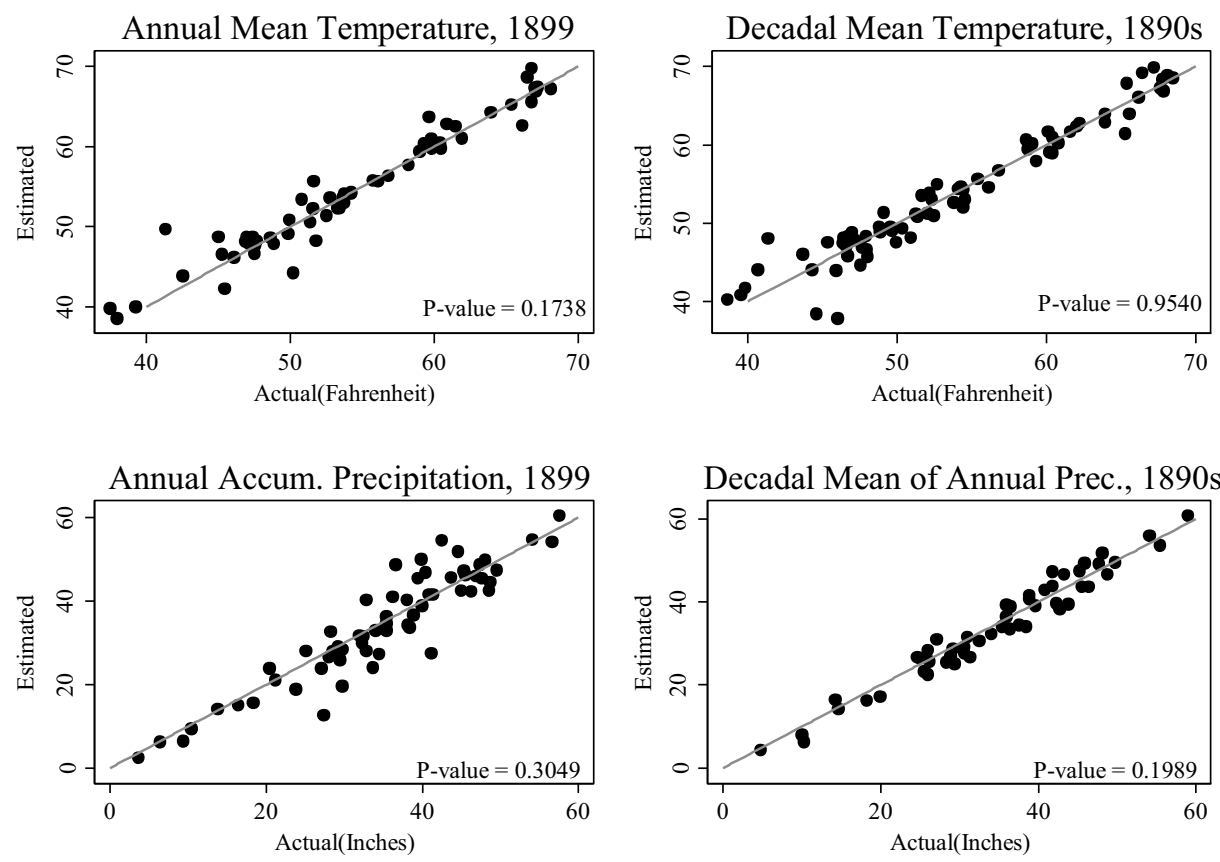

\section{APPENDIX FIGURE 1}

COMPARISON BETWEEN ACTUAL AND ESTIMATED WEATHER VARIABLES

Notes: In the figures, we test the validity of Kriging estimation for 60 counties randomly selected. We estimated their annual and decadal weather variables and compared with actual values. P-values denoted on the figures accept the null hypothesis that estimated and actual values are statistically the same. Each line on the figures is a 45-degree line. The correlation coefficients between estimated and actual values are 0.9699 (left) and 0.9683 (right) for the upper panel, and 0.9284 (left) and 0.9791 (right) on the lower panel.

Sources: Authors' calculations.

\section{Appendix 2: County-Level Agricultural, Economic, Demographic, and Environmental Data}

\section{Farm Productivity}

Two variables are used to measure U.S. farm productivity: farm value per farmland acre and farm output value per farmland acre. Farm value is the value of all land, housing, and outbuildings within the farm at the time of census enumeration; this can be interpreted as land price because the value of land on the farm accounts for a large portion of farm value, following hedonic studies. Farm output value is the total value of all farm products, such as crop and livestock products, within the year prior to the enumeration day. Both variables are generally obtained from Historical, Demographic, 
APPENDIX TABLE 1

SUMMARY STATISTICS: COUNTY WEATHER VARIABLES

\begin{tabular}{|c|c|c|c|c|c|c|c|c|c|}
\hline \multirow[b]{2}{*}{ Census Year } & \multirow[b]{2}{*}{ Year for Weather } & \multicolumn{4}{|c|}{ Mean Temperature $\left({ }^{\circ} \mathrm{F}\right)$} & \multicolumn{4}{|c|}{ Accumulated Precipitation (Inches) } \\
\hline & & Long-Term & S.E. & Short-Term & S.E. & Long-Term & S.E. & Short-Term & S.E. \\
\hline 1870 & 1869 & 54.2 & 5.7 & 54.2 & 6.9 & 41.8 & 6.6 & 44.3 & 10.1 \\
\hline 1880 & 1879 & 55.4 & 7.1 & 56.2 & 7.3 & 41.4 & 10.5 & 38.9 & 11.4 \\
\hline 1890 & 1889 & 54.7 & 7.3 & 55.4 & 7.2 & 41.8 & 10.4 & 39.5 & 11.9 \\
\hline 1900 & 1899 & 55.4 & 7.3 & 55.3 & 7.2 & 39.8 & 10.2 & 38.0 & 10.4 \\
\hline 1910 & 1909 & 55.3 & 7.2 & 55.6 & 7.6 & 41.4 & 10.0 & 42.5 & 11.2 \\
\hline 1920 & 1919 & 55.5 & 7.3 & 56.3 & 7.2 & 40.5 & 10.5 & 44.8 & 13.7 \\
\hline 1930 & 1929 & 56.0 & 7.5 & 55.1 & 7.8 & 41.8 & 11.2 & 45.8 & 16.0 \\
\hline 1940 & 1939 & 56.8 & 7.2 & 57.2 & 7.2 & 39.3 & 10.6 & 38.6 & 12.8 \\
\hline 1950 & 1949 & 56.1 & 7.1 & 56.9 & 7.1 & 42.1 & 10.9 & 43.0 & 13.3 \\
\hline 1960 & 1959 & 56.1 & 7.2 & 56.0 & 7.0 & 40.6 & 10.5 & 43.2 & 12.0 \\
\hline 1970 & 1969 & 55.0 & 7.0 & 54.6 & 6.9 & 39.9 & 11.0 & 41.4 & 10.5 \\
\hline 1980 & 1978 & 55.2 & 6.9 & 55.5 & 6.9 & 43.1 & 11.3 & 43.0 & 11.7 \\
\hline 1990 & 1987 & 55.1 & 6.9 & 56.4 & 6.1 & 42.6 & 10.0 & 39.1 & 10.2 \\
\hline 2000 & 1997 & 55.2 & 7.1 & 54.7 & 7.1 & 43.4 & 11.6 & 43.0 & 13.3 \\
\hline & All & 55.4 & 7.1 & 55.7 & 7.2 & 41.4 & 10.5 & 41.8 & 12.4 \\
\hline
\end{tabular}

Notes: Year for weather variable refers to the year when short-term weather variables were estimated, and which the years of long-term weather variables end in.

County-level monthly weather mean temperature and accumulated precipitation were estimated by Kriging interpolation methods as discussed in the text. This table presents sample means and standard errors across counties for the given census year or for all the years considered in this study. The long-term weather variables are calculated by the 10-year average of annual mean temperature and annual accumulated precipitation prior to each census year; the short-term weather variables are measured by the annual mean temperature and accumulated precipitation in each census year. The number of counties in each census year is 2,108 .

Sources: Authors' calculations from the Kriging results that are estimated using the records of the Nineteenth-Century U.S. Climate Data Set Project developed by the National Climate Data Center and the Long-Term Daily and Monthly Climate Records from the Stations across the Contiguous United States provided by the U.S. Historical Climatology Network. 
Economic, and Social Data: The United States, 1790-2002 (Haines and ICPSR 2010), which digitized the key variables in the U.S. federal population and agricultural censuses from 1850 to 1930 and U.S. county data books from 1940 to 2000 . We tried to construct the variables for the 14 decades from 1870 to 2000 , but the variables of county-level farm output value are missing from the ICPSR dataset for the three decades from 1910 to 1930. All values are converted in constant 2000 U.S. dollars using the BLS GDP deflator.

\section{Controls}

The long-period analysis substantially limits the use of various controls that might account for historical changes in the relationship between climate and farm productivity. We constructed a panel of four variables at the county level from 1870 to 2000: population density, the ratio of the white population to the total county population, the ratio of farmland to the total available county area, and the estimated number of farmers per farmland acre. The first three variables were obtained from the dataset of Haines and ICPSR (2010) mentioned earlier. To estimate the number of farmers per farmland acre, we first calculated the county ratio of farmers from the IPUMS dataset, a census subsample, and applied the ratio to the actual population per farmland acre. Sample means of each farm-productivity measure and controls by census year are reported in Appendix Table 2.

\section{Boundaries of Consistent Counties}

Changes in county boundaries over time can make fixed-effects analyses by county problematic. We thus adjusted all the county variables from 1880 to 2000 on the 1870 county boundary by tracking the overlap of county boundaries across decades and using the (overlapped) area-weighted average method. Appendix 3 shows that the use of county boundary-adjusted data does not cause critical problems in estimating fixedeffects models.

\section{Appendix 3: Supplementary Analyses}

\section{Fixed-Effects Analysis Using Data with the County Boundary Adjustment}

Throughout this study, we use county boundary-adjusted data in estimating county fixed-effects regressions, as discussed in Appendix 2. Using boundary-adjusted data, columns (1) and (3) in Appendix Table 3 present the estimated coefficients of the interaction terms between each weather variable and each year dummy, and their standard errors, clustered on county, after regressing equation (1) with county fixed effects. These coefficients are also graphically depicted by solid lines in Figure 2. In columns (2) and (4), we conduct the same regressions but use data without the county boundary adjustment. No substantial difference is found between the estimation results with and without the adjustment. 
APPENDIX TABLE 2

SUMMARY STATISTICS: FARM PRODUCTIVITY MEASURES AND CONTROLS

Productivity Measures

(in 2000 \$)

Controls

\begin{tabular}{|c|c|c|c|c|c|c|}
\hline Census Year & $\begin{array}{l}\text { Farm Value Per } \\
\text { Farmland Acres }\end{array}$ & $\begin{array}{l}\text { Farm Output Value } \\
\text { Per Farmland Acres }\end{array}$ & Population Density & $\begin{array}{l}\text { Ratio of White } \\
\text { Population }\end{array}$ & $\begin{array}{l}\text { Farm Acres out of } \\
\text { Total County Acres }\end{array}$ & $\begin{array}{l}\text { Num. of Farmers Per } \\
\text { Farmland Acres }\end{array}$ \\
\hline 1870 & 271.4 & 82.3 & 0.0297 & 0.8338 & 0.5425 & 0.0169 \\
\hline 1880 & 327.6 & 75.2 & 0.0372 & 0.8293 & 0.6639 & 0.0157 \\
\hline 1890 & 461.2 & 87.9 & 0.0434 & 0.8350 & 0.6809 & 0.0108 \\
\hline 1900 & 480.4 & 111.2 & 0.0508 & 0.8368 & 0.7481 & 0.0170 \\
\hline 1910 & 698.5 & & 0.0573 & 0.8444 & 0.7433 & 0.0188 \\
\hline 1920 & 748.5 & & 0.0633 & 0.8561 & 0.7236 & 0.0168 \\
\hline 1930 & 605.6 & & 0.0702 & 0.8548 & 0.6814 & 0.0173 \\
\hline 1940 & 709.7 & 125.3 & 0.0752 & 0.8693 & 0.6961 & 0.0132 \\
\hline 1950 & 642.2 & 184.2 & 0.0847 & 0.8772 & 0.7040 & 0.0305 \\
\hline 1960 & 931.5 & 219.5 & 0.1000 & 0.8799 & 0.6338 & 0.0204 \\
\hline 1970 & 1276.6 & 270.4 & 0.1140 & 0.8879 & 0.5736 & 0.0399 \\
\hline 1980 & 2482.5 & 402.1 & 0.1268 & 0.8823 & 0.5327 & 0.0115 \\
\hline 1990 & 1653.8 & 338.0 & 0.1406 & 0.8606 & 0.4987 & 0.0094 \\
\hline 2000 & 2878.4 & 412.8 & 0.1564 & 0.8533 & 0.4780 & 0.0115 \\
\hline
\end{tabular}

Notes: This table presents each census year's sample mean of farm productivity variables and standard control variables. The source of each variable is discussed in the text. Two productivity measures in monetary value are converted to constant 2000 U.S. dollars using the BLS GDP deflator. Population density is measured by the number of populations per square miles divided by 1,000 .

Sources: Authors' calculations based on two historical records: Historical, Demographic, Economic, and Social Data: The United States, $1790-2002$ (Haines and ICPSR 2010), and the IPUMS dataset (Ruggles et al. 2015). 
APPENDIX TABLE 3

THE EFFECTS OF LONG-TERM TEMPERATURE AND PRECIPITATION ON FARM VALUE: USING DATA WITH AND WITHOUT COUNTY BOUNDARY ADJUSTMENT

\begin{tabular}{|c|c|c|c|c|c|c|c|c|}
\hline \multicolumn{9}{|c|}{ Dependent Variable: $\ln ($ county average farm value per acre) } \\
\hline \multirow[b]{4}{*}{ Key Control Variables } & \multicolumn{4}{|c|}{ Weather $=$ Decadal Average of Annual Mean Temperature } & \multicolumn{4}{|c|}{ Weather $=$ Decadal Average of Annual Accumulated Precipitation } \\
\hline & \multirow{2}{*}{\multicolumn{2}{|c|}{$\begin{array}{c}\text { (1) } \\
\text { Using County-Boundary- } \\
\text { Adjusted Data }\end{array}$}} & \multicolumn{2}{|c|}{ (2) } & \multicolumn{2}{|c|}{$(3)$} & \multicolumn{2}{|c|}{ (4) } \\
\hline & & & \multicolumn{2}{|c|}{ Using Data without Adjustment } & \multicolumn{2}{|c|}{$\begin{array}{c}\text { Using County-Boundary- } \\
\text { Adjusted Data }\end{array}$} & \multicolumn{2}{|c|}{ Using Data without Adjustment } \\
\hline & Coeff. & S.E. & Coeff. & S.E. & Coeff. & S.E. & Coeff. & S.E. \\
\hline Weather & -0.0465 & 0.0110 & -0.0446 & 0.0107 & -0.0168 & 0.0067 & -0.0138 & 0.0058 \\
\hline Weather* $\mathrm{D}_{1880}$ & 0.0284 & 0.0072 & 0.0263 & 0.0073 & 0.0111 & 0.0056 & 0.0100 & 0.0054 \\
\hline Weather* $\mathrm{D}_{1890}$ & 0.0341 & 0.0083 & 0.0325 & 0.0085 & 0.0109 & 0.0062 & 0.0092 & 0.0057 \\
\hline Weather* $D_{1900}$ & 0.0407 & 0.0089 & 0.0384 & 0.0090 & 0.0135 & 0.0069 & 0.0121 & 0.0062 \\
\hline Weather* $\mathrm{D}_{1910}$ & 0.0484 & 0.0094 & 0.0482 & 0.0095 & 0.0073 & 0.0070 & 0.0060 & 0.0062 \\
\hline Weather* $D_{1920}$ & 0.0435 & 0.0097 & 0.0423 & 0.0096 & 0.0052 & 0.0071 & 0.0032 & 0.0060 \\
\hline Weather* $\mathrm{D}_{1930}$ & 0.0557 & 0.0099 & 0.0540 & 0.0096 & 0.0098 & 0.0073 & 0.0061 & 0.0058 \\
\hline Weather* $\mathrm{D}_{1940}$ & 0.0530 & 0.0096 & 0.0525 & 0.0093 & 0.0164 & 0.0072 & 0.0122 & 0.0057 \\
\hline Weather* $\mathrm{D}_{1950}$ & 0.0649 & 0.0099 & 0.0643 & 0.0098 & 0.0138 & 0.0072 & 0.0104 & 0.0060 \\
\hline Weather* $\mathrm{D}_{1960}$ & 0.0740 & 0.0099 & 0.0763 & 0.0098 & 0.0191 & 0.0073 & 0.0162 & 0.0062 \\
\hline Weather* $\mathrm{D}_{1970}$ & 0.0750 & 0.0099 & 0.0740 & 0.0098 & 0.0283 & 0.0073 & 0.0254 & 0.0061 \\
\hline Weather* $\mathrm{D}_{1980}$ & 0.0757 & 0.0097 & 0.0725 & 0.0096 & 0.0254 & 0.0069 & 0.0223 & 0.0060 \\
\hline Weather* $\mathrm{D}_{1990}$ & 0.0711 & 0.0097 & 0.0703 & 0.0096 & 0.0266 & 0.0071 & 0.0227 & 0.0061 \\
\hline Weather* $\mathrm{D}_{2000}$ & 0.0721 & 0.0096 & 0.0717 & 0.0093 & 0.0269 & 0.0073 & 0.0218 & 0.0059 \\
\hline Adj. $\mathrm{R}^{2}$ & \multicolumn{2}{|c|}{0.947} & \multicolumn{2}{|c|}{0.946} & \multicolumn{2}{|c|}{0.947} & \multicolumn{2}{|c|}{0.945} \\
\hline
\end{tabular}

Notes: We ran the fixed-effect estimation regression, per equation (1), for two datasets with and without a county boundary adjustment. Each regression is a weighted regression. The number of counties used in the regression is 29,512. The table reports only the coefficients of temperature or precipitation (denoted by Weather above) and its interaction with year dummies $\left(D_{\text {year }}\right)$. Standard errors are clustered on county. All the coefficients are statistically significant at the 99 percent level of confidence. The results in columns (1) and (3) are graphically presented by solid lines in Figure 2.

Sources: Authors' calculations. 
APPENDIX TABLE 4

EFFECT OF COUNTY BOUNDARY CHANGE

(1)

(3)

\begin{tabular}{lccc}
\hline \hline & $(1)$ & $(2)$ & $(3)$ \\
\cline { 2 - 4 } Key Variable & Baseline & $\begin{array}{c}\text { Using only Counties } \\
\text { without Boundary Changes }\end{array}$ & $\begin{array}{c}\text { Non-Southern Counties } \\
\text { from Baseline Sample }\end{array}$ \\
\hline Panel A: $Y=$ Farm Value, $T=$ Decadal Temperature & \\
\hline$T \times D_{19}$ & $-0.0470^{* * *}$ & $-0.0213^{* * *}$ & $-0.0273^{* * *}$ \\
& $(0.0056)$ & $(0.0076)$ & $(0.0065)$ \\
\hline Panel B: $Y=$ Farm Value, $P=$ Decadal Precipitation & $-0.0164^{* * *}$ \\
\hline$P \times D_{19}$ & $-0.0162^{* * *}$ & $-0.0156^{* * *}$ & $(0.0036)$ \\
\hline Panel C: $Y=$ Farm Output Value, $T=$ Annual Temperature & -0.0153 \\
\hline$T \times D_{19}$ & $-0.0416^{* * *}$ & -0.0035 & $(0.0098)$ \\
\hline Panel D: $Y=$ Farm Output Value, $P=$ Annual Precipitation & \\
\hline$P \times D_{19}$ & $-0.0114^{* * *}$ & $-0.0052^{*}$ & -0.0049 \\
& $(0.0031)$ & $(0.0027)$ & $(0.0044)$ \\
\hline Observations & 16,864 & 5,232 & 8,656 \\
\hline
\end{tabular}

$*=$ Significant at the 90 percent level.

** = Significant at the 95 percent level.

$* * *=$ Significant at the 99 percent level.

Notes: We estimate the level of agricultural adaptation to weather, which we examined in Tables 1 and 2, using alternative weather variables and specifications as explained in the head of columns. Panels A and B estimate the relationship between county farm value and decadal weather variables, and Panels $C$ and $D$ regard that between county farm output value and annual weather variables. The specification of each regression is the same as that of column (4) of Panel A or B in Tables 1 and 2, where we adopted the baseline results in column (1). We report only the coefficient of weather variables interacted with the dummy variable that indicates the census years in the nineteenth century. The standard errors of regression coefficients, reported in parentheses, are clustered on county.

Sources: Authors' calculations.

\section{Effect of County Boundary Change}

The county boundary change adjustment may miss the fact that the sample area and data can change much over the period of this study, with different types of climate in new areas. To see whether this can affect the key findings of this study, we constructed a balanced panel including counties whose boundaries have not changed from 1870 to 2000. By analyzing the change of county boundaries on GIS, we found 654 counties out of 2,323 in 1870 that satisfy the condition and constructed a balanced panel. We report the estimation result of using the balance panel in column (2) of Appendix Table 4. The result shows that the adaptation has occurred more substantially but that the magnitude of adaptation is estimated as somewhat smaller than that of the baseline estimation in column (1), particularly in the effect on farm output value. This may be because a small number of southern counties are contained in the balanced panel (only 24 out of 654 counties).

In fact, the earlier result is very similar to that in column (3) of Appendix Table 4, where we run the same regression only with non-southern counties from the baseline 
sample (in other words, boundary-adjusted sample). This implies that the change of county boundaries does not critically affect the level of agricultural adaptation or the implications of this article.

\section{REFERENCES}

Adams, Richard M. "Global Change and Agriculture: An Economic Perspective." American Journal of Agricultural Economics 71, no. 5 (1989): 1272-79.

Adams, Richard M., Cynthia Rosenzweig, Robert M. Pearl, et al. "Global Climate Change and U.S. Agriculture." Nature 345, no. 6272 (1990): 219-24.

Almond, Douglas. "Is the 1918 Influenza Pandemic Over? Long-Term Effects of In Utero Influenza Exposure in the Post-1940 U.S. Population." Journal of Political Economy 114, no. 4 (2006): 672-712.

Barker, David J. P. Mothers, Babies, and Disease in Later Life. London: BMJ Publishing Group, 1994.

Barreca, Alan. "The Long-Term Economic Impact of In Utero and Postnatal Exposure to Malaria." Journal of Human Resources 45, no. 4 (2010): 865-92.

Barreca, Alan, Karen Clay, Olivier Deschênes, et al. "Convergence in Adaptation to Climate Change: Evidence from High Temperatures and Mortality, 1900-2004." American Economic Review: Papers \& Proceedings 105, no. 5 (2015): 247-51.

Black, Sandra E., Paul J. Devereux, and Kjell G. Salvanes. "From the Cradle to the Labor Market? The Effect of Birth Weight on Adult Outcomes." Quarterly Journal of Economics 122, no. 1 (2007): 409-39.

Bleakley, Hoyt. "Disease and Development: Evidence from Hookworm Eradication in the American South." Quarterly Journal of Economics 122, no. 1 (2007): 73-117.

_. "Malaria Eradication in the Americas: A Retrospective Analysis of Childhood Exposure." American Economic Journal: Applied 2, no. 2 (2010):1-45.

Burke, Marshall, Solomon Hsiang, and Edward Miguel. "Global Non-linear Effect of Temperature on Economic Production.” Nature 527 (2015): 235-39.

Carter, Susan B., Scott S. Gartner, Michael R. Haines, et al. Historical Statistics of the United States: Millennial Edition. Cambridge: Cambridge University Press, 2006.

Cline, William R. "The Impact of Global Warming of Agriculture: Comment." American Economic Review 86, no. 5 (1996): 1309-11.

Costa, Dora L. "Race and Pregnancy Outcomes in the Twentieth Century: A LongTerm Comparison.” Journal of Economic History 64, no. 4 (2004): 1056-86.

Darwin, Roy. "The Impact of Global Warming on Agriculture: A Ricardian Analysis: Comment." American Economic Review 89, no. 4 (1999): 1049-52.

Dell, Melissa, Benjamin F. Jones, and Benjamin A. Olken. "Temperature Shocks and Economic Growth: Evidence from the Last. Half Century." American Economic Journal: Macroeconomics 4, no. 3 (2012): 66-95.

Desai, Meghna, Feiko O Ter Kuile, Francois Nosten, et al. "Epidemiology and Burden of Malaria in Pregnancy." Lancet Infectious Diseases 7, no. 2 (2007): 93-104.

Deschênes, Olivier, and Michael Greenstone. "The Economic Impacts of Climate Change: Evidence from Agricultural Output and Random Fluctuations in Weather." American Economic Review 97, no. 1 (2007): 354-85.

Deschênes, Olivier, Michael Greenstone, and Jonathan Guryan. "Climate Change and Birth Weight." American Economic Review 99, no. 2 (2009): 211-17. 
Diamond, Jared. Guns, Germs, and Steel: The Fates of Human Societies. New York: W.W. Northern and Company, 1997.

Gardner, Bruce L. American Agriculture in the Twentieth Century: How It Flourished and What It Cost. Cambridge: Harvard University Press, 2009.

Guiteras, Raymond. “The Impact of Climate Change on Indian Agriculture.” Mimeo, 2009.

Haines, Michael R., and ICPSR. Historical, Demographic, Economic, and Social Data: The United States, 1790-2002 (ICPSR 02896-v3). Ann Arbor, MI: Inter-university Consortium for Political and Social Research, 2010. Machine-readable database.

Holding, P. A., and R. W. Snow. "Impact of Plasmodium Falciparum Malaria on Performance and Learning: Review of the Evidence." American Journal of Tropical Medicine and Hygiene 64, no. 1-2 S (2001): 68-75.

Hong, Sok Chul. "The Burden of Early Exposure to Malaria in the United States, 1850 1860: Malnutrition and Immune Disorders.” Journal of Economic History 67, no. 4 (2007): 1001-35.

_. "Malaria and Economic Productivity: A Longitudinal Analysis of the American Case." Journal of Economic History 71, no. 3 (2011): 654-71.

- "Malaria: An Early Indicator of Later Disease and Work Level." Journal of Health Economics 32, no. 3 (2013): 612-32.

Hornbeck, Richard. "The Enduring Impact of the American Dust Bowl: Short- and Long-Run Adjustments to Environmental Catastrophe." American Economic Review 102, no. 4 (2012): 1477-507.

Houghton, John T., G.J. Jenkins, and J.J. Ephraums, eds. Climate Change: The IPCC Scientific Assessment. New York: Cambridge University Press, 1990.

Lafferty, Kevin D. "The Ecology of Climate Change and Infectious Diseases." Ecology 90, no. 4 (2009): 888-900.

Lawlor, Debbie A., David A. Leon, and George D. Smith. "The Association of Ambient Outdoor Temperature throughout Pregnancy and Offspring Birthweight: Findings from the Aberdeen Children of the 1950s Cohort." BJOG: An International Journal of Obstetrics and Gynaecology 112, no. 5 (2005): 647-57.

Libecap, Gary D. "The Assignment of Property Rights on the Western Frontier: Lessons for Contemporary Environmental and Resource Policy." Journal of Economic History 67, no. 2 (2007): 257-91.

Maccini, Sharon, and Dean Yang. "Under the Weather: Health, Schooling, and Economic Consequences of Early-Life Rainfall." American Economic Review 99, no. 3 (2009): 1006-26.

Mendelsohn, Robert, William D. Nordhaus, and Daigee Shaw. "The Impact of Global Warming on Agriculture: A Ricardian Analysis.” American Economic Review 84, no. 4 (1994): 753-71.

Murray, L. J., D. P. O’Reilly, N. Betts, et al. “Season and Outdoor Ambient Temperature: Effects on Birth Weight." Obstetrics and Gynecology 96, no. 5 (2000): 689-95.

Olmstead, Alan L., and Paul W. Rhode. Creating Abundance: Biological Innovation and American Agricultural Development. New York: Cambridge University Press, 2008.

- "Adapting North American Wheat Production to Climatic Challenges, 18392009." PNAS 108, no. 2 (2011): 480-85.

Ó Gráda, Cormac. "Making Famine History.” Journal of Economic Literature 45, no. 1 (2007): 5-38. 
Patz, Jonathan A., Diarmid Campbell-Lendrum, Tracey Holloway, et al. "Impact of Regional Climate Change on Human Health.” Nature 438, no. 17 (2005): 310-17.

Ruggles, Steven, Katie Genadek, Ronald Goeken, et al. Integrated Public Use Microdata Series: Version 6.0. Minneapolis, MN: University of Minnesota, 2015. Machinereadable database.

Sachs, Jeffrey, and Pia Malaney. "The Economic and Social Burden of Malaria." Nature 415 (2002): 680-85.

Schlenker, Wolfram, and Michael J. Roberts. "Nonlinear Temperature Effects Indicate Severe Damages to U.S. Crop Yields under Climate Change." Proceedings of the National Academy of Sciences of the United States of America 106, no. 37 (2009): 15594-98.

Schlenker, Wolfram, W. Michael Hanemann, and Anthony C. Fisher. "Will U.S. Agriculture Really Benefit from Global Warming?: Accounting for Irrigation in the Hedonic Approach." American Economic Review 95, no. 1 (2005): 395-406.

- "The Impact of Global Warming on U.S. Agriculture: An Econometric Analysis." Review of Economics and Statistics 88, no. 1 (2006): 113-25.

Stein, Michael L. Interpolation of Spatial Data: Some Theory for Kriging. New York: Springer, 1999.

Thomas, Chris D., Alison Cameron, Rhys E. Green, et al. "Extinction Risk from Climate Change." Nature 427, no. 8 (2003): 145-48.

U.S. Bureau of Census. Report on the Productions of Agriculture as Returned at the Tenth Census (June 1, 1880). Washington, DC: GPO, 1883.

-U.S. Census of Agriculture: 1950. Vol. V, Special Reports, Part 6. Washington, DC: GPO, 1952.

World Health Organization, WMO, and UNEP. Climate Change and Human HealthRisks and Responses. Geneva: World Health Organization, 2003. 